\title{
Calculation of the Isobaric Heat Capacities of the Liquid and Solid Phase of Organic Compounds at 298.15K by Means of the Group-Additivity Method
}

\author{
Rudolf Naef \\ Department of Chemistry, University of Basel, 4003 Basel, Switzerland; rudolf.naef@unibas.ch; \\ Tel.: 41-619-119-273
}

Received: 5 February 2020; Accepted: 2 March 2020; Published: 4 March 2020

\begin{abstract}
The calculation of the isobaric heat capacities of the liquid and solid phase of molecules at $298.15 \mathrm{~K}$ is presented, applying a universal computer algorithm based on the atom-groups additivity method, using refined atom groups. The atom groups are defined as the molecules' constituting atoms and their immediate neighbourhood. In addition, the hydroxy group of alcohols are further subdivided to take account of the different intermolecular interactions of primary, secondary, and tertiary alcohols. The evaluation of the groups' contributions has been carried out by solving a matrix of simultaneous linear equations by means of the iterative Gauss-Seidel balancing calculus using experimental data from literature. Plausibility has been tested immediately after each fitting calculation using a 10-fold cross-validation procedure. For the heat capacity of liquids, the respective goodness of fit of the direct $\left(r^{2}\right)$ and the cross-validation calculations $\left(q^{2}\right)$ of 0.998 and 0.9975 , and the respective standard deviations of 8.24 and $9.19 \mathrm{~J} / \mathrm{mol} / \mathrm{K}$, together with a mean absolute percentage deviation (MAPD) of $2.66 \%$, based on the experimental data of 1111 compounds, proves the excellent predictive applicability of the present method. The statistical values for the heat capacity of solids are only slightly inferior: for $r^{2}$ and $q^{2}$, the respective values are 0.9915 and 0.9874 , the respective standard deviations are 12.21 and $14.23 \mathrm{~J} / \mathrm{mol} / \mathrm{K}$, and the MAPD is $4.74 \%$, based on 734 solids. The predicted heat capacities for a series of liquid and solid compounds have been directly compared to those received by a complementary method based on the "true" molecular volume and their deviations have been elucidated.
\end{abstract}

Keywords: heat capacity; group-additivity method; ionic liquids

\section{Introduction}

Most experimental measurements of thermodynamic properties, such as vaporization, sublimation, solvation, or fusion enthalpies, are usually carried out at temperatures that differ from the standard temperature, which has generally been accepted as being $298.15 \mathrm{~K}$. These temperature differences lead to experimental values for the temperature-dependent properties that prevent a direct comparison of the results between various compounds or between scientific teams examining the same molecule, a deficiency which, however, can be corrected, provided that the heat capacity of the molecules under examination is known. Instead of measuring this property for a specific molecule, the large amount of experimental heat-capacity data for all kinds of compounds, such as inorganic and organic salts, liquid crystals, or ionic liquids, enabled its prediction by means of a large number of mathematical methods, a comprehensive overview of which has been given in a recent publication by the present author [1]. The majority of these prediction methods are based on the group-additivity (GA) approach, whereby the group notations vary from complete polyatomic ions as, e.g., applied by Gardas and Coutinho [2] to single atoms and their immediate neighbour atoms and ligands, as described by 
Benson and Buss [3]. Generally, the GA methods' range of applicability for the prediction of any kind of descriptors varies over a large scope of molecular structures, depending on the complexity and number of the group notations as well as the number of experimental data upon which the group parameters are based. Similarly, the reliability of the predictions is highly dependent on the range of application. Zàbransky and Ruzicka [4], e.g., defined 130 functional groups including cis, trans, as well as ortho and meta corrections in the parametrization of their second-order polynomial GA model for the prediction of the liquid heat capacity and its temperature dependence, based on more than 1800 experimental data points. For the majority of compounds they reported an average deviation of below $2 \%$. For alkanols, acids and aldehydes, however, the error was larger than $3 \%$ and rose with increasing temperature. A further limit to the use of their model was the observation that the prediction accuracy deteriorated further if the compounds contained functional groups from different families, such as $N, N^{\prime}$-diethanolamine or 1-chloro-2-propanol. Another example of a GA method, provided by Chickos et al. [5], used 47 functional groups for the prediction calculation of the heat capacity of 810 liquids and 446 solids, reporting standard errors of $19.5 \mathrm{~J} / \mathrm{molK}$ for the liquids and $26.9 \mathrm{~J} / \mathrm{mol} / \mathrm{K}$ for the solids. The authors compared these errors with the experimental uncertainties of 8.12 and $23.4 \mathrm{~J} / \mathrm{mol} / \mathrm{K}$, respectively, which they estimated from the experimental data variations for each of 219 liquids and 102 solids published by independent sources.

A common deficiency of the GA and all the other approaches cited in [1] is that none of them enables the prediction of any specific descriptor for each and any molecular structure in the chemical realm. In the case of the heat capacities of the solid and liquid phase of molecules, however, this deficiency has been overcome in that their prediction values are determined via the "true" molecular volume $\left(\mathrm{V}_{\mathrm{m}}\right)$ outlined in detail in [1]. Nevertheless, this approach has encountered several other shortcomings which could not all be addressed specifically, as it is based on one single number, the molecular volume. The three most important deficiencies are 1) the general influence of the hydroxy group of alcohols and carboxylic acids, 2) the specific effects of primary, secondary, and tertiary alcohols and 3) the impact of saturated cyclic rings vs. open-chained systems on the heat capacities. Accordingly, a first attempt of a linear correlation calculation in [1], which included the molecular volume and the experimental liquid heat capacity $\mathrm{C}_{\mathrm{p}}$ (liq) of the complete set of compounds, for which both data were available, and which neglected the mentioned shortcomings, yielded a rather large standard deviation of $27.84 \mathrm{~J} / \mathrm{mol} / \mathrm{K}$ and a mean absolute percentage deviation (MAPD) of $8.23 \%$. The neglect of the hydroxy-group effect on $\mathrm{C}_{\mathrm{p}}(\mathrm{liq})$ was immediately manifest in that the predicted values for all those compounds carrying at least one $\mathrm{OH}$ group were systematically well below the experimental ones by up to ca. $130 \mathrm{~J} / \mathrm{mol} / \mathrm{K}$. This general deviation, obviously caused by the formation of intermolecular hydrogen bridges between the $\mathrm{OH}$ groups, has been considered in subsequent calculations in that the complete set of compounds was separated by means of a few simple steps in the computer algorithm into three subsets, i.e., one encompassing all molecules lacking any $\mathrm{OH}$ group, a second one consisting of those carrying one $\mathrm{OH}$ group and a third one comprising those having more than one $\mathrm{OH}$ group. For each of these subsets, a separate linear correlation calculation had to be carried out yielding three sets of linear parameters for the prediction of the liquid and three for that of the solid heat capacities. In this way, the first one of the mentioned shortcomings has been eliminated, which correspondingly resulted in significantly better compliance of the predictions with the experimental data. The corresponding statistical results will be discussed and used for comparison in a later section. The remaining two deficiencies concerning the various alcohol classes as well as that of cyclic vs. open-chained structures in a saturated system, which exhibit a minor but still systematically negative influence on the prediction quality, has been plausibly explained, but a reasonably straightforward treatment within the context of the $\mathrm{V}_{\mathrm{m}}$ method was not feasible.

Therefore, the question arose as to whether and how well a GA approach would overcome the remaining shortcomings of the $\mathrm{V}_{\mathrm{m}}$ method and enable a more accurate and reliable prediction of the heat capacities of molecules in their liquid and solid phase at the standard temperature, in awareness of the disadvantage that it would not be able to cover each and every possible compound. 
A particularly versatile GA method, outlined in [6], enabling in a single sweep the calculation of 14 thermodynamic [6,7], solubility- [6-8], optics- [6], charge- [6], environment-related [6], and physical $[8,9]$ properties of a nearly unlimited scope and size of molecular structures should best serve this purpose, all the more so as in most cases it in principle also opened a simple means for their reliable calculation on a sheet of paper. Accordingly, the present work puts a special focus on the effects of the hydroxy groups and the cyclization of saturated molecular parts on the heat capacities and how to deal with them. The statistical results of the present GA method will be put in relation to those of the $V_{m}$ method but also to those of the GA approach of Chickos et al. [5], as this approach can be viewed as most closely related to the present one.

\section{Method}

The present study is founded on a project-owned and regularly updated, object-oriented database of more than 32000 molecules encompassing pharmaceuticals, plant protection, dyes, ionic liquids, liquid crystals, metal-organics, lab intermediates, and many more, all of which are stored as geometry-optimized 3-dimensional structures, including-besides several further descriptors-a set of 1176 experimental heat capacities of liquids and a corresponding set of 802 heat capacities of solids.

The details of the present atom-group additivity method and the evaluation of its group contributions have been outlined in an earlier paper [6]. Accordingly, its group notations have the same meaning as that exemplified in Table 1 of [6]. However, in order to include ionic liquids for which the experimental heat capacities are known, the list of group notations has been extended by ionic atom groups representing their charged fragments, as listed in the present Table 1. These special atom groups have already successfully been utilized in the calculation of the molecules' viscosity [8] and surface tension [9], applied in the same way as the remaining groups. For the interpretation of the ionic atom groups of Table 1, the reader is invited to read section 2 of papers [8] and [9].

Table 1. Atom-group examples for ionic liquids and their meaning.

\begin{tabular}{|c|c|c|c|}
\hline Atom Type & Neighbours & Meaning $^{\mathrm{a}}$ & Example \\
\hline $\mathrm{B}(-)$ & $\mathrm{F} 4$ & $\mathrm{BF}_{4}^{-}$ & tetrafluoroborate \\
\hline C sp3 & $\mathrm{H} 2 \mathrm{CN}(+)$ & $\mathrm{CCH}_{2} \mathrm{~N}(+)$ & $\mathrm{C} 1$ in tetraalkylammonium \\
\hline C sp3 & $\mathrm{H} 2 \mathrm{CP}(+)$ & $\mathrm{CCH}_{2} \mathrm{P}(+)$ & C1 in tetraalkylphosphonium \\
\hline C sp3 & $\mathrm{H} 2 \mathrm{CS}(+)$ & $\mathrm{CCH}_{2} \mathrm{~S}(+)$ & $\mathrm{C} 1$ in trialkylsulfonium \\
\hline $\mathrm{C}(-) \mathrm{sp} 3$ & $\mathrm{C} 3$ & $\mathrm{C}_{3} \mathrm{C}^{-}$ & central $\mathrm{C}^{-}$in tricyanocarbeniate \\
\hline $\mathrm{C}$ aromatic & $\mathrm{H}: \mathrm{C}: \mathrm{N}(+)$ & $\mathrm{C}: \mathrm{CH}: \mathrm{N}^{+}$ & $\mathrm{C} 2$ in pyridinium \\
\hline $\mathrm{C}(+)$ aromatic & $\mathrm{H}: \mathrm{N} 2$ & $\mathrm{~N}: \mathrm{C}^{+} \mathrm{H}: \mathrm{N}$ & $\mathrm{C} 2$ in imidazolium \\
\hline C sp & $\mathrm{B} \# \mathrm{~N}(-)$ & $\mathrm{B}^{-}(\mathrm{C} \# \mathrm{~N})$ & C in tetracyanoborate \\
\hline C sp & $\mathrm{C} \# \mathrm{~N}(-)$ & $\mathrm{C}^{-}(\mathrm{C \# N})$ & cyano-C in tricyanocarbeniate \\
\hline C sp & $\mathrm{N \# N(-)}$ & $\mathrm{N}^{-}(\mathrm{C \# N})$ & $\mathrm{C}$ in dicyanoamide \\
\hline C sp & $=\mathrm{N}=\mathrm{S}(-)$ & $\mathrm{N}=\mathrm{C}=\mathrm{S}^{-}$ & thiocyanate \\
\hline $\mathrm{N}(+) \mathrm{sp} 3$ & $\mathrm{C} 4$ & $\mathbf{N}^{+} \mathrm{C}_{4}$ & tetraalkylammonium \\
\hline $\mathrm{N}(+) \mathrm{sp} 2$ & $\mathrm{O} 2=\mathrm{O}(-)$ & $\mathrm{NO}_{3}^{-}$ & nitrate \\
\hline $\mathrm{N}$ aromatic & $\mathrm{C} 2: \mathrm{C}(+)$ & $\mathrm{C}-\mathrm{N}(\mathrm{C}): \mathrm{C}^{+}$ & N1 and N3 in 1,3-dialkylimidazolium \\
\hline $\mathrm{N}(+)$ aromatic & $\mathrm{C}: \mathrm{C} 2$ & $C: \mathbf{N}^{+}(C): C$ & $\mathrm{~N}$ in 1-alkylpyridinium \\
\hline $\mathrm{N}(-)$ & $\mathrm{C} 2$ & $\mathrm{C}-\mathrm{N}^{-}-\mathrm{C}$ & $\mathrm{N}^{-}$in dicyanoamide \\
\hline $\mathrm{N}(-)$ & CS & $\mathrm{C}-\mathrm{N}^{-}-\mathrm{S}$ & $\mathrm{N}^{-}$in saccharinate \\
\hline$N(-)$ & S2 & S-N-N & bis(trifluoromethanesulfonyl)amide \\
\hline
\end{tabular}


Table 1. Cont.

\begin{tabular}{cccc}
\hline Atom Type & Neighbours & Meaning $^{\mathbf{a}}$ & Example \\
\hline $\mathrm{P} 4$ & $\mathrm{CO} 2=\mathrm{O}(-)$ & $\mathrm{CPO}^{-}$ & alkylphosphonate \\
\hline $\mathrm{P}(+)$ & $\mathrm{C} 4$ & $\mathbf{P C}_{4}{ }^{+}$ & tetraalkylphosphonium \\
\hline $\mathrm{P}(-)$ & $\mathrm{C} 3 \mathrm{~F} 3$ & $\mathrm{~F}_{3} \mathbf{P}^{-} \mathrm{C}_{3}$ & tris(pentafluoroethyl)trifluorophosphate \\
\hline $\mathrm{P}(-)$ & $\mathrm{F} 6$ & $\mathbf{P F}_{6}{ }^{-}$ & hexafluorophosphate \\
\hline $\mathrm{S}(+)$ & $\mathrm{C} 3$ & $\mathrm{C}_{3} \mathbf{S}^{+}$ & trialkylsulfonium \\
\hline $\mathrm{S} 4$ & $\mathrm{CN}=\mathrm{O} 2(-)$ & ${\mathrm{CS}\left(\mathrm{O}_{2}\right) \mathrm{N}^{-}}^{-}$ & bis(trifluoromethanesulfonyl)amide \\
\hline $\mathrm{S} 4$ & $\mathrm{CO}=\mathrm{O} 2(-)$ & $\mathrm{CSO}_{3}{ }^{-}$ & alkylsulfonate \\
\hline $\mathrm{S} 4$ & $\mathrm{O} 2=\mathrm{O} 2(-)$ & $\mathrm{SO}_{4}^{-}$ & alkylsulfate \\
\hline
\end{tabular}

a The central atom defined by the atom type is indicated by a bold character.

In the course of the first preliminary group-contribution calculations, whereby tentatively certain "standard" atom groups have been replaced by refined ones and special groups, which will be described in the following, have been added or omitted, their statistical results quickly revealed significant improvement of the predictive quality if the groups listed in Table 2 are included in the prediction of both the liquid and solid heat capacities.

Table 2. Refined atom and special groups and their meaning.

\begin{tabular}{|c|c|c|}
\hline Atom Type & Neighbours & Meaning \\
\hline $\mathrm{O}($ prim $)$ & $\mathrm{HC}$ & Primary alcohol \\
\hline $\mathrm{O}(\mathrm{sec})$ & $\mathrm{HC}$ & Secondary alcohol \\
\hline $\mathrm{O}$ (tert) & $\mathrm{HC}$ & Tertiary alcohol \\
\hline Endocyclic bonds & No of single bonds & Count single bonds in cyclic ring \\
\hline Angle60 & & Bond angle $<60 \mathrm{deg}$ \\
\hline Angle 90 & & Bond angle between 60 and $90 \mathrm{deg}$ \\
\hline Angle102 & & Bond angle between 90 and $102 \mathrm{deg}$ \\
\hline$(\mathrm{COH}) \mathrm{n}$ & $\mathrm{n}>1$ & Molecule contains more than $1 \mathrm{OH}$ group \\
\hline $\mathrm{H}$ & H Acceptor & $\begin{array}{l}\text { Intramolecular } \mathrm{H} \text { bridge between acidic } \mathrm{H} \\
\text { (on } \mathrm{O}, \mathrm{N} \text { or } \mathrm{S}) \text { and basic acceptor }(\mathrm{O}, \mathrm{N} \text { or } \mathrm{F})\end{array}$ \\
\hline
\end{tabular}

In the discussion of the shortcomings of the molecular volume-based calculations of the heat capacities outlined in the introductory section, the hydroxy group appeared to be the most accountable group for large deviations between experimental and predicted heat-capacity values, even within the restricted set of $\mathrm{OH}$-containing compounds, i.e., after their separation from the remaining ones. It turned out that the definition of the $\mathrm{OH}$ group on saturated carbon as in ordinary alcohols by the simple atom type "O" and its neighbours " $\mathrm{HC}^{\prime}$ " was inadequate for heat-capacity calculations, in contrast to the calculations of all the other descriptors mentioned in our earlier papers [6-9]. As a consequence, an additional procedure had to be integrated in the general GA algorithm outlined in [1], which redefined the atom type " $\mathrm{O}$ " into "O(prim)", " $\mathrm{O}(\mathrm{sec})$ ", or "O(tert)", depending on the number of carbon atoms attached to the $\mathrm{C}$ atom neighbouring the $\mathrm{O}$ atom, according to the definition of primary, secondary, and tertiary alcohols, as shown in Table 2. (Consequently, the definition of their neighbourhood " $\mathrm{HC}^{\prime}$ " was no longer relevant and was thus not examined.) This redefinition procedure is only invoked if the redefined atom types appear in the group-parameters table, as a consequence of the algorithmic procedure determining that it is the content of the group-parameter tables that defines which group parameters are to be evaluated for the corresponding descriptors calculations (as explained in subsection 2.2 of [1]), and since none of the other descriptors in [6-9] requires this redefinition, this procedure is only called up for the evaluation of the group parameters of present Table 3 and Table 7 and the subsequent heat-capacity predictions. The remaining hydroxy groups 
attached to unsaturated carbon found in carboxylic acids and phenols are notated separately by the atom type "O" and the neighbourhood " $\mathrm{HC}(\mathrm{pi})$ ", as defined in [6].

Table 3. Atom groups and their contributions for the heat-capacity calculation of liquids.

\begin{tabular}{|c|c|c|c|c|c|}
\hline Entry & Atom Type & Neighbours & Contribution & Occurrences & Molecules \\
\hline 1 & B & $\mathrm{C} 3$ & 240 & 1 & 1 \\
\hline 2 & $\mathrm{~B}(-)$ & $\mathrm{C} 4$ & 698.66 & 2 & 2 \\
\hline 3 & $\mathrm{~B}(-)$ & $\mathrm{F} 4$ & 51.21 & 6 & 6 \\
\hline 4 & C sp3 & H3C & 37.03 & 1555 & 790 \\
\hline 5 & C sp3 & H3N & 100.02 & 127 & 101 \\
\hline 6 & C sp3 & $\mathrm{H} 3 \mathrm{~N}(+)$ & 147.91 & 20 & 18 \\
\hline 7 & C sp3 & $\mathrm{H} 3 \mathrm{O}$ & 81.29 & 84 & 66 \\
\hline 8 & C sp3 & H3S & 84.43 & 17 & 13 \\
\hline 9 & C sp3 & H3S(+) & 172.17 & 1 & 1 \\
\hline 10 & C sp3 & $\mathrm{H} 3 \mathrm{P}$ & 217.59 & 1 & 1 \\
\hline 11 & C sp3 & $\mathrm{H} 3 \mathrm{Si}$ & 71 & 71 & 18 \\
\hline 12 & C sp3 & $\mathrm{H} 2 \mathrm{BC}$ & -37.03 & 3 & 1 \\
\hline 13 & C sp3 & $\mathrm{H} 2 \mathrm{C} 2$ & 30.06 & 3249 & 696 \\
\hline 14 & C sp3 & $\mathrm{H} 2 \mathrm{CN}$ & 90.52 & 222 & 146 \\
\hline 15 & C sp3 & $\mathrm{H} 2 \mathrm{CN}(+)$ & 142.85 & 78 & 52 \\
\hline 16 & C sp3 & $\mathrm{H} 2 \mathrm{CO}$ & 73.86 & 477 & 243 \\
\hline 17 & C sp3 & $\mathrm{H} 2 \mathrm{CS}$ & 75.25 & 38 & 27 \\
\hline 18 & C sp3 & $\mathrm{H} 2 \mathrm{CS}(+)$ & 136.25 & 29 & 10 \\
\hline 19 & C sp3 & $\mathrm{H} 2 \mathrm{CP}$ & 252.08 & 2 & 1 \\
\hline 20 & C sp3 & $\mathrm{H} 2 \mathrm{CP}(+)$ & 71.8 & 12 & 3 \\
\hline 21 & C sp3 & $\mathrm{H} 2 \mathrm{CCl}$ & 63.67 & 38 & 30 \\
\hline 22 & C sp3 & $\mathrm{H} 2 \mathrm{CBr}$ & 63.93 & 26 & 21 \\
\hline 23 & C sp3 & $\mathrm{H} 2 \mathrm{CJ}$ & 67.73 & 10 & 9 \\
\hline 24 & C sp3 & $\mathrm{H} 2 \mathrm{CSi}$ & 60.71 & 18 & 8 \\
\hline 25 & C sp3 & H2N2 & 151.55 & 4 & 2 \\
\hline 26 & C sp3 & $\mathrm{H} 2 \mathrm{NO}$ & 157.51 & 12 & 12 \\
\hline 27 & C sp3 & $\mathrm{H} 2 \mathrm{O} 2$ & 111.47 & 4 & 4 \\
\hline 28 & C sp3 & $\mathrm{H} 2 \mathrm{~S} 2$ & 128.41 & 1 & 1 \\
\hline 29 & C sp3 & $\mathrm{HC} 3$ & 21.11 & 303 & 196 \\
\hline 30 & C sp3 & $\mathrm{HC} 2 \mathrm{~N}$ & 81.86 & 14 & 14 \\
\hline 31 & C sp3 & $\mathrm{HC} 2 \mathrm{~N}(+)$ & 159.6 & 3 & 3 \\
\hline 32 & C sp3 & $\mathrm{HC} 2 \mathrm{O}$ & 67.45 & 107 & 87 \\
\hline 33 & C sp3 & $\mathrm{HC} 2 \mathrm{~S}$ & 67.46 & 10 & 9 \\
\hline 34 & C sp3 & $\mathrm{HC} 2 \mathrm{Si}$ & 36.48 & 1 & 1 \\
\hline 35 & C sp3 & $\mathrm{HC} 2 \mathrm{Cl}$ & 56.56 & 9 & 9 \\
\hline 36 & C sp3 & $\mathrm{HC} 2 \mathrm{Br}$ & 56.84 & 4 & 4 \\
\hline 37 & C sp3 & HC2J & 62.21 & 2 & 2 \\
\hline
\end{tabular}


Table 3. Cont.

\begin{tabular}{|c|c|c|c|c|c|}
\hline Entry & Atom Type & Neighbours & Contribution & Occurrences & Molecules \\
\hline 38 & C sp3 & $\mathrm{HCNO}(+)$ & 176.8 & 3 & 1 \\
\hline 39 & C sp3 & $\mathrm{HCO} 2$ & 96.7 & 3 & 3 \\
\hline 40 & C sp3 & HCF2 & 157.26 & 1 & 1 \\
\hline 41 & C sp3 & $\mathrm{HCFCl}$ & 73.89 & 1 & 1 \\
\hline 42 & C sp3 & $\mathrm{HCCl} 2$ & 86.15 & 9 & 8 \\
\hline 43 & C sp3 & $\mathrm{HCClBr}$ & 89.68 & 1 & 1 \\
\hline 44 & C sp3 & HCBr2 & 82.85 & 2 & 1 \\
\hline 45 & C sp3 & $\mathrm{C} 4$ & 7.78 & 62 & 51 \\
\hline 46 & C sp3 & $\mathrm{C} 3 \mathrm{~N}$ & 81.33 & 5 & 4 \\
\hline 47 & C sp3 & $\mathrm{C} 3 \mathrm{~N}(+)$ & 55.23 & 3 & 3 \\
\hline 48 & C sp3 & $\mathrm{C} 3 \mathrm{O}$ & 57.44 & 23 & 21 \\
\hline 49 & C sp3 & C3S & 57.43 & 7 & 5 \\
\hline 50 & C sp3 & $\mathrm{C} 3 \mathrm{~F}$ & 43.66 & 5 & 3 \\
\hline 51 & C sp3 & $\mathrm{C} 3 \mathrm{Cl}$ & 50.92 & 1 & 1 \\
\hline 52 & C sp3 & $\mathrm{C} 3 \mathrm{Br}$ & 54.62 & 1 & 1 \\
\hline 53 & C sp3 & C2N2(+) & 223.66 & 2 & 2 \\
\hline 54 & C sp3 & $\mathrm{C} 2 \mathrm{O} 2$ & 99.71 & 1 & 1 \\
\hline 55 & C sp3 & $\mathrm{C} 2 \mathrm{~F} 2$ & 50.88 & 78 & 13 \\
\hline 56 & C sp3 & $\mathrm{C} 2 \mathrm{FCl}$ & 64.31 & 5 & 2 \\
\hline 57 & C sp3 & $\mathrm{C} 2 \mathrm{Cl} 2$ & 87.42 & 2 & 2 \\
\hline 58 & C sp3 & CNF2 & 112.99 & 3 & 1 \\
\hline 59 & C sp3 & CF3 & 66.92 & 31 & 23 \\
\hline 60 & C sp3 & CSF2 & 0 & 1 & 1 \\
\hline 61 & C sp3 & CPF2(-) & 44.23 & 6 & 2 \\
\hline 62 & C sp3 & $\mathrm{CF} 2 \mathrm{Cl}$ & 89.67 & 4 & 4 \\
\hline 63 & C sp3 & $\mathrm{CF} 2 \mathrm{Br}$ & 86.41 & 7 & 4 \\
\hline 64 & C sp3 & $\mathrm{CFCl} 2$ & 88.11 & 3 & 2 \\
\hline 65 & C sp3 & $\mathrm{CCl} 3$ & 102.55 & 8 & 8 \\
\hline 66 & C sp3 & SF3 & 102.78 & 151 & 78 \\
\hline 67 & $C(-) \operatorname{sp} 3$ & C3 & 131.76 & 1 & 1 \\
\hline 68 & C sp2 & $\mathrm{H} 2=\mathrm{C}$ & 35.64 & 61 & 59 \\
\hline 69 & C sp2 & $\mathrm{HC}=\mathrm{C}$ & 22.79 & 195 & 107 \\
\hline 70 & C sp2 & $\mathrm{HC}=\mathrm{N}$ & 95.94 & 4 & 4 \\
\hline 71 & C sp2 & $\mathrm{HC}=\mathrm{O}$ & 54.97 & 23 & 23 \\
\hline 72 & C sp2 & $\mathrm{H}=\mathrm{CN}$ & 92.25 & 166 & 87 \\
\hline 73 & C sp2 & $\mathrm{H}=\mathrm{CO}$ & 42.8 & 11 & 10 \\
\hline 74 & C sp2 & $\mathrm{H}=\mathrm{CS}$ & 87.41 & 5 & 5 \\
\hline 75 & C sp2 & $\mathrm{H}=\mathrm{CCl}$ & 56.41 & 5 & 3 \\
\hline 76 & C sp2 & $\mathrm{H}=\mathrm{CSi}$ & 43.69 & 4 & 4 \\
\hline 77 & C sp2 & $\mathrm{HN}=\mathrm{N}$ & 32.91 & 3 & 3 \\
\hline
\end{tabular}


Table 3. Cont.

\begin{tabular}{|c|c|c|c|c|c|}
\hline Entry & Atom Type & Neighbours & Contribution & Occurrences & Molecules \\
\hline 78 & C sp2 & $\mathrm{HN}=\mathrm{O}$ & 100.63 & 3 & 3 \\
\hline 79 & C sp2 & $\mathrm{HO}=\mathrm{O}$ & 58.82 & 7 & 7 \\
\hline 80 & C sp2 & $\mathrm{H}=\mathrm{NS}$ & 15.48 & 2 & 2 \\
\hline 81 & C sp2 & $\mathrm{C} 2=\mathrm{C}$ & 16.22 & 54 & 44 \\
\hline 82 & C sp2 & $\mathrm{C} 2=\mathrm{N}$ & 333.48 & 1 & 1 \\
\hline 83 & C sp2 & $\mathrm{C}=\mathrm{CN}$ & 89.61 & 3 & 2 \\
\hline 84 & C sp2 & $\mathrm{C} 2=\mathrm{O}$ & 50.28 & 49 & 49 \\
\hline 85 & C sp2 & $\mathrm{C}=\mathrm{CO}$ & 36.16 & 5 & 5 \\
\hline 86 & C sp2 & $\mathrm{C}=\mathrm{CS}$ & 74.31 & 5 & 4 \\
\hline 87 & C sp2 & $\mathrm{C}=\mathrm{CCl}$ & 160.28 & 1 & 1 \\
\hline 88 & C sp2 & $\mathrm{CN}=\mathrm{O}$ & 87.09 & 12 & 12 \\
\hline 89 & C sp2 & $\mathrm{CN}=\mathrm{O}(-)$ & 87.78 & 1 & 1 \\
\hline 90 & C sp2 & $\mathrm{C}=\mathrm{NS}$ & 8.06 & 1 & 1 \\
\hline 91 & C sp2 & $\mathrm{CO}=\mathrm{O}$ & 43.25 & 216 & 158 \\
\hline 92 & C sp2 & $\mathrm{CO}=\mathrm{O}(-)$ & 27.63 & 8 & 7 \\
\hline 93 & C sp2 & $\mathrm{C}=\mathrm{OS}$ & 0 & 1 & 1 \\
\hline 94 & C sp2 & $\mathrm{C}=\mathrm{OCl}$ & 70.53 & 7 & 6 \\
\hline 95 & C sp2 & $=\mathrm{CF} 2$ & 56.5 & 2 & 1 \\
\hline 96 & C sp2 & $=\mathrm{CCl} 2$ & 77.26 & 5 & 4 \\
\hline 97 & C sp2 & $\mathrm{N} 2=\mathrm{N}$ & 56.88 & 1 & 1 \\
\hline 98 & C sp2 & $\mathrm{N} 2=\mathrm{O}$ & 131.83 & 3 & 3 \\
\hline 99 & C sp2 & $\mathrm{NO}=\mathrm{O}$ & 98.32 & 1 & 1 \\
\hline 100 & C sp2 & $\mathrm{O} 2=\mathrm{O}$ & 50.04 & 5 & 5 \\
\hline 101 & $\mathrm{C}$ aromatic & $\mathrm{H}: \mathrm{C} 2$ & 22 & 1115 & 238 \\
\hline 102 & C aromatic & $\mathrm{H}: \mathrm{C}: \mathrm{N}$ & 42.32 & 19 & 13 \\
\hline 103 & $\mathrm{C}$ aromatic & $\mathrm{H}: \mathrm{C}: \mathrm{N}(+)$ & -9.45 & 53 & 32 \\
\hline 104 & C aromatic & $\mathrm{H}: \mathrm{N} 2$ & 0 & & 0 \\
\hline 105 & $\mathrm{C}$ aromatic & :C3 & 9.57 & 19 & 11 \\
\hline 106 & $\mathrm{C}$ aromatic & $\mathrm{C}: \mathrm{C} 2$ & 11.58 & 251 & 152 \\
\hline 107 & $\mathrm{C}$ aromatic & $C: C: N$ & 30.59 & 8 & 7 \\
\hline 108 & $\mathrm{C}$ aromatic & $\mathrm{C}: \mathrm{C}: \mathrm{N}(+)$ & -2.69 & 11 & 11 \\
\hline 109 & $\mathrm{C}$ aromatic & :C2N & 71.34 & 31 & 29 \\
\hline 110 & C aromatic & :C2N(+) & 118.05 & 11 & 8 \\
\hline 111 & C aromatic & $: \mathrm{C} 2 \mathrm{~N}$ & 31.72 & 3 & 3 \\
\hline 112 & C aromatic & :C2O & 33.82 & 46 & 28 \\
\hline 113 & C aromatic & :C2S & 88.68 & 7 & 7 \\
\hline 114 & C aromatic & :C2Si & 37.2 & 10 & 7 \\
\hline 115 & C aromatic & $: \mathrm{C} 2 \mathrm{~F}$ & 37.06 & 54 & 17 \\
\hline 116 & $\mathrm{C}$ aromatic & $: \mathrm{C} 2 \mathrm{Cl}$ & 41.28 & 19 & 15 \\
\hline 117 & $\mathrm{C}$ aromatic & $: \mathrm{C} 2 \mathrm{Br}$ & 52.57 & 11 & 8 \\
\hline
\end{tabular}


Table 3. Cont.

\begin{tabular}{|c|c|c|c|c|c|}
\hline Entry & Atom Type & Neighbours & Contribution & Occurrences & Molecules \\
\hline 118 & $\mathrm{C}$ aromatic & :C2J & 43.43 & 3 & 3 \\
\hline 119 & $\mathrm{C}(+)$ aromatic & $\mathrm{H}: \mathrm{N} 2$ & -155.06 & 74 & 74 \\
\hline 120 & C sp & $\mathrm{B \# N(-)}$ & -130.93 & 8 & 2 \\
\hline 121 & C sp & $\mathrm{H \# C}$ & 38.78 & 6 & 5 \\
\hline 122 & C sp & C\#C & 23.99 & 10 & 7 \\
\hline 123 & $\mathrm{Csp}$ & $=\mathrm{C} 2$ & 25.16 & 4 & 4 \\
\hline 124 & $\mathrm{Csp}$ & $\mathrm{C \# N}$ & 48.78 & 35 & 31 \\
\hline 125 & C sp & C\#N(-) & -9.81 & 3 & 1 \\
\hline 126 & $\mathrm{Csp}$ & \#CSi & 49.58 & 2 & 1 \\
\hline 127 & C sp & N\#N(-) & -2.88 & 12 & 6 \\
\hline 128 & C sp & $=\mathrm{N} 2$ & -89.69 & 1 & 1 \\
\hline 129 & $C \mathrm{sp}$ & $=\mathrm{N}=\mathrm{O}$ & -20.75 & 8 & 5 \\
\hline 130 & C sp & $=\mathrm{N}=\mathrm{S}(-)$ & 43.63 & 3 & 3 \\
\hline 131 & $\mathrm{~N} \mathrm{sp3}$ & $\mathrm{H} 2 \mathrm{C}$ & -4.35 & 33 & 28 \\
\hline 132 & N sp3 & H2C(pi) & 0.31 & 9 & 9 \\
\hline 133 & $\mathrm{~N} \mathrm{sp3}$ & $\mathrm{H} 2 \mathrm{~N}$ & 48.67 & 5 & 4 \\
\hline 134 & $\mathrm{~N} \mathrm{sp3}$ & $\mathrm{HC} 2$ & -71.79 & 21 & 20 \\
\hline 135 & $\mathrm{~N} \mathrm{sp3}$ & HC2(pi) & -72.44 & 14 & 14 \\
\hline 136 & N sp3 & HC2(2pi) & -103.28 & 6 & 6 \\
\hline 137 & N sp3 & $\mathrm{HCN}$ & -15.74 & 4 & 3 \\
\hline 138 & $\mathrm{~N} \mathrm{sp3}$ & $\mathrm{HCN}(\mathrm{pi})$ & -13 & 1 & 1 \\
\hline 139 & N sp3 & HCS(pi) & -21.52 & 1 & 1 \\
\hline 140 & N sp3 & C3 & -160.23 & 33 & 28 \\
\hline 141 & N sp3 & C3(pi) & -149.65 & 17 & 14 \\
\hline 142 & N sp3 & C3(2pi) & -180.02 & 3 & 3 \\
\hline 143 & N sp3 & C3(3pi) & -165.46 & 1 & 1 \\
\hline 144 & N sp3 & $\mathrm{C} 2 \mathrm{~N}$ & -91.6 & 2 & 2 \\
\hline 145 & N sp3 & $\mathrm{C} 2 \mathrm{~N}(2 \mathrm{pi})$ & -143.37 & 2 & 2 \\
\hline 146 & N sp3 & C2N(3pi) & -160.71 & 1 & 1 \\
\hline 147 & $\mathrm{~N} \mathrm{sp} 2$ & $\mathrm{H}=\mathrm{C}$ & -243.13 & 1 & 1 \\
\hline 148 & $\mathrm{~N} \mathrm{sp} 2$ & $C=C$ & 15.82 & 17 & 13 \\
\hline 149 & $\mathrm{~N} \mathrm{sp} 2$ & $\mathrm{C}=\mathrm{N}$ & -20.24 & 2 & 1 \\
\hline 150 & $\mathrm{~N} \mathrm{sp} 2$ & $\mathrm{C}=\mathrm{N}(+)$ & -42.22 & 1 & 1 \\
\hline 151 & $\mathrm{~N} \mathrm{sp} 2$ & $=\mathrm{CN}$ & 0 & 3 & 3 \\
\hline 152 & N sp2 & $=\mathrm{CO}$ & -53.43 & 1 & 1 \\
\hline 153 & $\mathrm{~N}$ aromatic & $\mathrm{C} 2: \mathrm{C}(+)$ & -0.31 & 148 & 74 \\
\hline 154 & $\mathrm{~N}$ aromatic & :C2 & -16.75 & 15 & 15 \\
\hline 155 & $\mathrm{~N}(+) \mathrm{sp} 3$ & $\mathrm{H} 3 \mathrm{C}$ & -44.33 & 1 & 1 \\
\hline 156 & $\mathrm{~N}(+) \mathrm{sp} 3$ & $\mathrm{H} 2 \mathrm{C} 2$ & -140.41 & 4 & 4 \\
\hline 157 & $\mathrm{~N}(+) \mathrm{sp} 3$ & HC3 & -291.64 & 1 & 1 \\
\hline
\end{tabular}


Table 3. Cont

\begin{tabular}{|c|c|c|c|c|c|}
\hline Entry & Atom Type & Neighbours & Contribution & Occurrences & Molecules \\
\hline 158 & $\mathrm{~N}(+) \mathrm{sp} 3$ & $\mathrm{C} 4$ & -372.93 & 13 & 13 \\
\hline 159 & $\mathrm{~N}(+) \mathrm{sp} 2$ & $\mathrm{C}=\mathrm{NO}(-)$ & 0 & 1 & 1 \\
\hline 160 & $\mathrm{~N}(+) \mathrm{sp} 2$ & $\mathrm{CO}=\mathrm{O}(-)$ & -45.71 & 25 & 17 \\
\hline 161 & $\mathrm{~N}(+) \mathrm{sp} 2$ & $\mathrm{O} 2=\mathrm{O}(-)$ & 5.99 & 4 & 4 \\
\hline 162 & $\mathrm{~N}(+)$ aromatic & $\mathrm{C}: \mathrm{C} 2$ & 14.22 & 32 & 32 \\
\hline 163 & $N(-)$ & $\mathrm{C} 2$ & 62.36 & 6 & 6 \\
\hline 164 & $\mathrm{~N}(-)$ & CS & -32.57 & 1 & 1 \\
\hline 165 & $N(-)$ & S2 & 33.36 & 73 & 73 \\
\hline 166 & $\mathrm{O}$ (prim) & $\mathrm{HC}$ & 14.35 & 102 & 89 \\
\hline 167 & $\mathrm{O}(\mathrm{sec})$ & $\mathrm{HC}$ & 36.17 & 47 & 47 \\
\hline 168 & $\mathrm{O}$ (tert) & $\mathrm{HC}$ & 58 & 11 & 11 \\
\hline 169 & $\mathrm{O}$ & $\mathrm{HC}(\mathrm{pi})$ & 48.39 & 57 & 46 \\
\hline 170 & $\mathrm{O}$ & $\mathrm{HP}$ & -119.34 & 1 & 1 \\
\hline 171 & $\mathrm{O}$ & HS & 39.11 & 1 & 1 \\
\hline 172 & $\mathrm{O}$ & $\mathrm{C} 2$ & -59.32 & 170 & 98 \\
\hline 173 & $\mathrm{O}$ & C2(pi) & -26.57 & 191 & 149 \\
\hline 174 & $\mathrm{O}$ & C2(2pi) & -15.47 & 22 & 12 \\
\hline 175 & $\mathrm{O}$ & $\mathrm{CN}(+)(\mathrm{pi})$ & 55.55 & 3 & 3 \\
\hline 176 & $\mathrm{O}$ & CN(2pi) & 0 & 1 & 1 \\
\hline 177 & $\mathrm{O}$ & CS & 16.03 & 8 & 8 \\
\hline 178 & $\mathrm{O}$ & $\mathrm{CP}(\mathrm{pi})$ & 22.25 & 3 & 1 \\
\hline 179 & $\mathrm{O}$ & $\mathrm{CSi}$ & -22.04 & 20 & 5 \\
\hline 180 & $\mathrm{O}$ & $\mathrm{Si} 2$ & -21.83 & 19 & 7 \\
\hline 181 & P4 & $\mathrm{C} 2 \mathrm{O}=\mathrm{O}(-)$ & -344.96 & 1 & 1 \\
\hline 182 & P4 & $\mathrm{CO} 2=\mathrm{O}(-)$ & 0 & 1 & 1 \\
\hline 183 & $\mathrm{P} 4$ & $\mathrm{O} 3=\mathrm{O}$ & 0 & 1 & 1 \\
\hline 184 & $\mathrm{P}(+)$ & $\mathrm{C} 4$ & -95.06 & 3 & 3 \\
\hline 185 & $\mathrm{P}(-)$ & C3F3 & 33.12 & 2 & 2 \\
\hline 186 & $\mathrm{P}(-)$ & F6 & 96.53 & 9 & 9 \\
\hline 187 & S2 & $\mathrm{HC}$ & 0.94 & 19 & 19 \\
\hline 188 & $\mathrm{~S} 2$ & $\mathrm{HC}(\mathrm{pi})$ & -25.44 & 1 & 1 \\
\hline 189 & S2 & $\mathrm{C} 2$ & -53.94 & 19 & 19 \\
\hline 190 & S2 & C2(pi) & -77.07 & 2 & 2 \\
\hline 191 & S2 & C2(2pi) & -89.86 & 7 & 7 \\
\hline 192 & S2 & CS & -11.11 & 8 & 4 \\
\hline 193 & S4 & $\mathrm{C} 2=\mathrm{O}$ & -23.45 & 2 & 2 \\
\hline 194 & S4 & $\mathrm{C} 2=\mathrm{O} 2$ & -18.86 & 1 & 1 \\
\hline 195 & S4 & $\mathrm{CN}=\mathrm{O} 2$ & 0 & 1 & 1 \\
\hline 196 & S4 & $\mathrm{CN}=\mathrm{O} 2(-)$ & 5.69 & 147 & 74 \\
\hline 197 & S4 & $\mathrm{CO}=\mathrm{O} 2(-)$ & 4.61 & 9 & 9 \\
\hline
\end{tabular}


Table 3. Cont.

\begin{tabular}{|c|c|c|c|c|c|}
\hline Entry & Atom Type & Neighbours & Contribution & Occurrences & Molecules \\
\hline 198 & S4 & $\mathrm{O} 2=\mathrm{O} 2(-)$ & 0 & 9 & 9 \\
\hline 199 & $\mathrm{~S}(+)$ & $\mathrm{C} 3$ & -203.28 & 10 & 10 \\
\hline 200 & $\mathrm{Si}$ & $\mathrm{C} 4$ & -89.09 & 11 & 10 \\
\hline 201 & $\mathrm{Si}$ & $\mathrm{C} 3 \mathrm{O}$ & -49.41 & 6 & 3 \\
\hline 202 & $\mathrm{Si}$ & $\mathrm{C} 3 \mathrm{Cl}$ & -25.49 & 1 & 1 \\
\hline 203 & $\mathrm{Si}$ & $\mathrm{C} 2 \mathrm{O} 2$ & 9.5 & 16 & 6 \\
\hline 204 & $\mathrm{Si}$ & $\mathrm{C} 2 \mathrm{Cl} 2$ & 25.44 & 3 & 3 \\
\hline 205 & $\mathrm{Si}$ & $\mathrm{CCl} 3$ & 86.83 & 3 & 3 \\
\hline 206 & $\mathrm{Si}$ & $\mathrm{O} 4$ & 0 & 5 & 5 \\
\hline 207 & $(\mathrm{COH}) \mathrm{n}$ & $\mathrm{n}>1$ & -27.73 & 20 & 19 \\
\hline 208 & $\mathrm{H}$ & H Acceptor & -21.43 & 3 & 3 \\
\hline 209 & Endocyclic bonds & No of single bds & -3.92 & 1341 & 243 \\
\hline 210 & Angle60 & & 4.13 & 69 & 19 \\
\hline 211 & Angle90 & & 1.7 & 63 & 19 \\
\hline A & Based on & Valid groups & 134 & & 1176 \\
\hline B & Goodness of fit & $r^{2}$ & 0.998 & & 1111 \\
\hline $\mathrm{C}$ & Deviation & Average & 6.09 & & 1111 \\
\hline $\mathrm{D}$ & Deviation & Standard & 8.24 & & 1111 \\
\hline $\mathrm{E}$ & K-fold cv & K & 10 & & 1060 \\
\hline $\mathrm{F}$ & Goodness of fit & $q^{2}$ & 0.9975 & & 1060 \\
\hline G & Deviation & Average (cv) & 6.85 & & 1060 \\
\hline $\mathrm{H}$ & Deviation & Standard (cv) & 9.19 & & 1060 \\
\hline
\end{tabular}

Another point of weakness discussed in the introductory section rested in the observation that the $\mathrm{V}_{\mathrm{m}}$ approach systematically scored badly in the prediction of the heat capacities of molecules with cyclic saturated moieties. This deficiency has been resolved in the present GA method in that the endocyclic single bonds in a molecule are counted and their sum multiplied by the contribution value of the special group "Endocyclic bonds" to yield the effect of the cyclic moieties in a molecule on its heat capacity. The groups "Angle60", "Angle90", and "Angle102" serve as corrective elements for small rings. Not surprisingly, these special groups, which take account of an effect influencing the freedom of intramolecular motion, have also successfully been applied in the prediction of the entropy of fusion [7].

The special group " $(\mathrm{COH}) n$ " had to be introduced in the $\mathrm{C}_{\mathrm{p}}$ calculations in order to compensate for deviations found for polyols and polyacids. This special group has played its useful part already in the calculation of the surface tension [9]. The test calculations also revealed a very strong influence of intramolecular hydrogen bonds on the liquid heat capacity, which had to be taken into account by the introduction of the special group "H/H Acceptor", a group that has also been used successfully used in the prediction of the toxicity [6], the heats of solvation, and the sublimation, vaporization, and entropy of fusion [7].

The procedure for the evaluation of the atom-group contributions, as explained in [6], is identical for the two group-parameter sets for the prediction of the heat capacities of both the liquid and solid phases and may be summarized as follows: in a first step, a list of all the compounds, for which the experimental $C_{p}$ values are known, is extracted from the database. In the next step, each "backbone" 
atom (i.e., each atom bound to at least two immediate neighbours) within each molecule has an atom type and its neighbourhood assigned to by means of two character strings defining an atom group, following the rules defined in [6] (e.g., "C sp3" and "H2CO" for the $\mathrm{C}_{1}$ atom in ethanol) and then this group's occurrence in the molecule is counted. The list of $\mathrm{M}$ molecules and their $\mathrm{N}$ atom groups plus their experimental values are then entered into an $\mathrm{M} \times(\mathrm{N}+1)$ matrix, wherein each matrix element $(i, j)$ receives the number of occurrences of the $j$ th atomic or special group in the $i$ th molecule. The normalization of this matrix into an $\mathrm{Ax}=\mathrm{B}$ matrix and its balancing by means of the Gauss-Seidel calculus, e.g., according to E. Hardtwig [10], yields the atom-group contributions. This mathematical approach is based on the assumption that the prediction value of a molecule's descriptor in question can be evaluated by simply summing up all the group contributions in the molecule. For the evaluation of the heat capacities in this study, Equation 1 has been adopted, wherein $C_{p}$ is the heat capacity at $298.15 \mathrm{~K}, a_{i}$ and $b_{j}$ are the group contributions, $A_{i}$ is the number of occurrences of the $i$ th atom group, and $B_{j}$ is the number of occurrences of the $j$ th special group.

$$
C_{p}=\sum_{i} a_{i} A_{i}+\sum_{j} b_{j} B_{j}
$$

The reliance of this procedure is immediately examined by a subsequent 10 -fold cross-validation plausibility test, carried out in a way to ensure that each compound has been entered into the calculation as a test as well as a training sample. All the group contribution values and the statistical results of both the direct equalization and the cross-validation calculation of the liquid heat capacity $C_{p}(l i q, 298)$ are then collected in Table 3 and for the solid heat capacity $C_{p}($ sol,298) in Table 7. However, for the evaluation of the statistical results, only those group contributions are considered as valid for use that have been represented by at least three independent molecules in the equalization calculation. The number of molecules responsible for the respective group contribution is listed in the rightmost column of Table 3 and Table 7. Evidently, for several atom groups, this number falls short of the validity requirement. Nevertheless, as this work is part of a continuous project, these groups have deliberately remained in the parameters' tables for future use. They might also motivate readers working in this area to contribute corresponding experimental data. In order to achieve reliable contribution values for the atom and special groups, it was necessary to filter out compounds with $C_{p}$ values that deviated too far from the predicted results. In the present work, the limit was defined as three times the cross-validated standard deviation $q^{2}$. The corresponding outliers have been excluded from the parameters' calculations and are collected in an outliers list. The present calculations are generally restricted to molecules containing the elements $\mathrm{H}, \mathrm{B}, \mathrm{C}, \mathrm{N}, \mathrm{O}, \mathrm{P}, \mathrm{S}, \mathrm{Si}$, and/or halogen.

\section{Sources of Heat-Capacity Data}

The present work is essentially based on the comprehensive list of experimental heat-capacities collected in [1], used to substantiate the feasibility of the $V_{m}$ approach. However, a recent scan of the literature brought forth a number of further publications, which either confirmed previous data or even improved the conformance with prediction, but also enabled an extension of the applicability of the present GA approach. A number of new experimental $C_{p}$ data have been published for saturated and unsaturated hydrocarbons, especially for bicyclo[2.2.2]octane and bicyclo[2.2.2]octene [11], 1-octyne and 4-octyne [12], biphenyl [13], benzo[b]fluoranthene, benzo[k]fluoranthene, indeno[1,2,3-cd]pyrene [14], and adamantane [15]. In addition, further $C_{p}$ values have been found for the amines hexamethylenetetramine [15], tetra- $N$-phenylbenzidine and 4,4'-bis ( $N$-carbazolyl)-1,1'-biphenyl [16], 1,3,5-triazine [17], the ethers 1,3,5-trioxane [17], diethylene glycol n-pentyl ether [18], triethylene glycol monopentyl ether [19] and diphenyl ether [20], several alcohols and aldehydes [21], derivatives of glycidol [22], carboxylic acids [23,24], aliphatic esters [24-27], benzoates [28], haloalkanes [29,30], haloaromatics [31,32], thio ethers, sulfones and sulfoxides [33,34], alkanolamines, [35-37] and nitriles [38] For several compounds, more recent publications have been 
found the following: 4-ethylmorpholine [39], methionine [40], theophylline, and caffeine [41], as well as for (-)-menthone, (+)-pulegone, and (-)-isopulegol [42]. Beyond these, experimental $C_{p}$ values of a number of new compounds have been published: namely 3-amino-4-amidoximinofurazan [43], 3-fluoro-5-(3-pyridinyloxy)- benzenamine and $N$-[3-fluoro-5-(3-pyridinyloxy)phenyl]- $N$ '-3-pyridinyl urea [44], 7-Methyl-1,5,7-triazabicyclo[4.4.0]dec-5-ene [45], 2-[(4-nitro-benzoyl)-hydrazone]-propionic acid [46], eugenol and (+)-carvone [47], indapamide [48], and the explosives EDNH and DNTA [49]. For some silicon-containing compounds, new $\mathrm{C}_{\mathrm{p}}$ data have been found in [50]. Finally, a few further heat capacities data of ionic liquids [51-53] have been included in the present dataset.

\section{Results}

\subsection{General Remarks}

1. In the subsequent figures, the results of the cross-validation calculations have been superimposed in red over the training data drawn in black.

2. The complete lists of compounds with known heat capacities used in this study are available as SDF files in the Supplementary Materials, downloadable by external chemistry software. In addition, the Supplementary Materials provides the results lists containing the molecules' names and experimental, training, and cross-validation data. Beyond this, the lists of outliers of both heat-capacity calculations are also available in the Supplementary Materials.

\subsection{Heat Capacity of Liquids}

In Table 3, the atom groups and their contribution for the prediction of the heat capacity of liquids are collected, together with the number of molecules and occurrences upon which each of them is based.

In rows $\mathrm{A}$ to $\mathrm{H}$, at the bottom of the table, the statistical data of this table have been gathered. As shown in row A, the group contributions have been evaluated on the basis of 1176 compounds yielding the data for 211 atom groups, of which, however, only 134 are considered as valid, i.e., that are supported by at least three compounds. Accordingly, since only valid groups have been used for the statistical evaluations, the numbers of compounds entered in the calculations of the trained and cross-validated correlation coefficients ("goodness of fit") $r^{2}$ and $q^{2}$ (rows B and F) are lower with 1111 and 1060, respectively. Both the standard deviations of the complete data set (row D) as well as that of the combined cross-validation sets (row H) reveal excellently low values (in $\mathrm{J} / \mathrm{mol} / \mathrm{K}$ ), not only in relation to the large range of experimental values of between 81.92 (methanol) and $1849 \mathrm{~J} / \mathrm{mol} / \mathrm{K}$ (trimethylpropane trioleate), but particularly also in comparison with the standard error of $19.5 \mathrm{~J} / \mathrm{mol} / \mathrm{K}$ reported by Chickos et al. [5] for 810 liquids. The result is a very low scatter along the correlation line, as is shown in Figure 1. Accordingly, the error distributions of both the training and the cross-validated sets fairly well follow the Gaussian distribution function, as demonstrated in the histogram (Figure 2). The MAPD for the complete set of 1111 liquid compounds was $2.66 \%$, clearly by far better than the $8.23 \%$ for the entire set of 1303 liquids resulting from the $V_{m}$ method [1], and still much better in comparison with the $6.51 \%$ for the $\mathrm{OH}$-free subset of 1102 liquids reported in Figure 2 of [1]. 


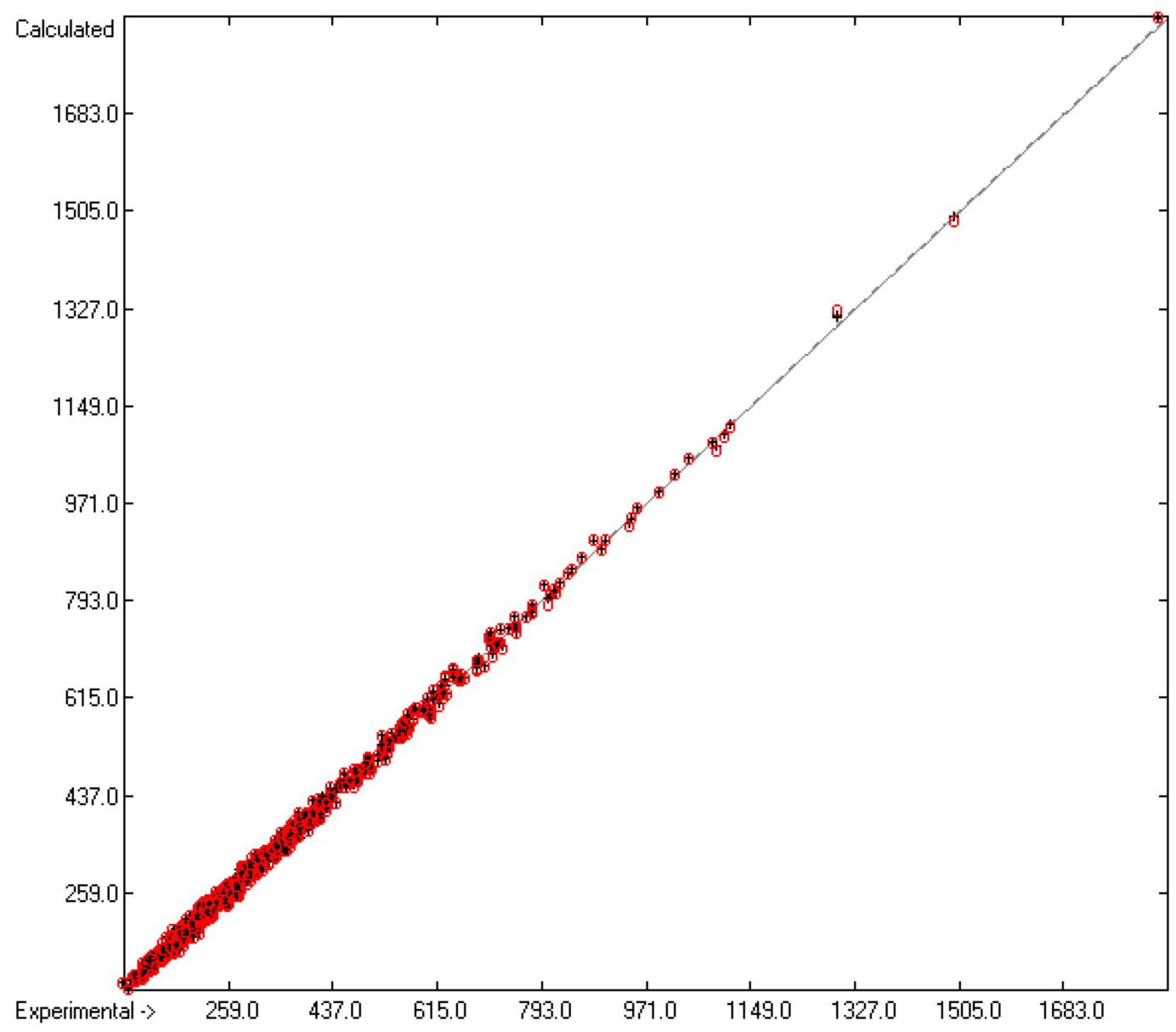

Figure 1. Correlation diagram of the $C_{p}($ liq, 298) data (in $\mathrm{J} / \mathrm{mol} / \mathrm{K})$. The cross-validation data are superimposed as red circles. $\left(n=1111 ; r^{2}=0.998 ; q^{2}=0.9975\right.$; regression line: intercept $=0.7993$; slope $=0.9977)$.

The distinctly better conformance of the predicted with the experimental $C_{p}($ liq) values in comparison with earlier literature references is essentially based on three primary reasons. The first one is the refinement of the molecules' description itself by the most detailed classification of group notations, which is precluded on principal to the $\mathrm{V}_{\mathrm{m}}$ method [1], but requires a large number of atom groups and consequently a large amount of experimental data for their parametrization. The second reason originated from an observation made in [1], namely that the heat capacities of primary, and less so, of secondary alcohols have notoriously been overestimated by the $\mathrm{V}_{\mathrm{m}}$ approach. These systematic deviations can be seen in Table 4 , where the experimental $C_{p}($ liq,298) data and the predicted values of both the present GA and $V_{m}$ method of the corresponding alkanols, encompassing saturated alkyl mono-, di- and polyols, are compiled for comparison. In order to overcome this deficiency, the alcohols have therefore been subdivided as described in Section 2 into the three subclasses primary, secondary, and tertiary alcohols. This additional separation indeed had a dramatically positive effect on the entire alcohols class, demonstrated by the comparison of the correlation diagrams of Figure 3. The MAPD values shown at the bottom of Table 4 confirm that the GA method on average produces distinctly lower deviations from experimental values than the $\mathrm{V}_{\mathrm{m}}$ approach. 


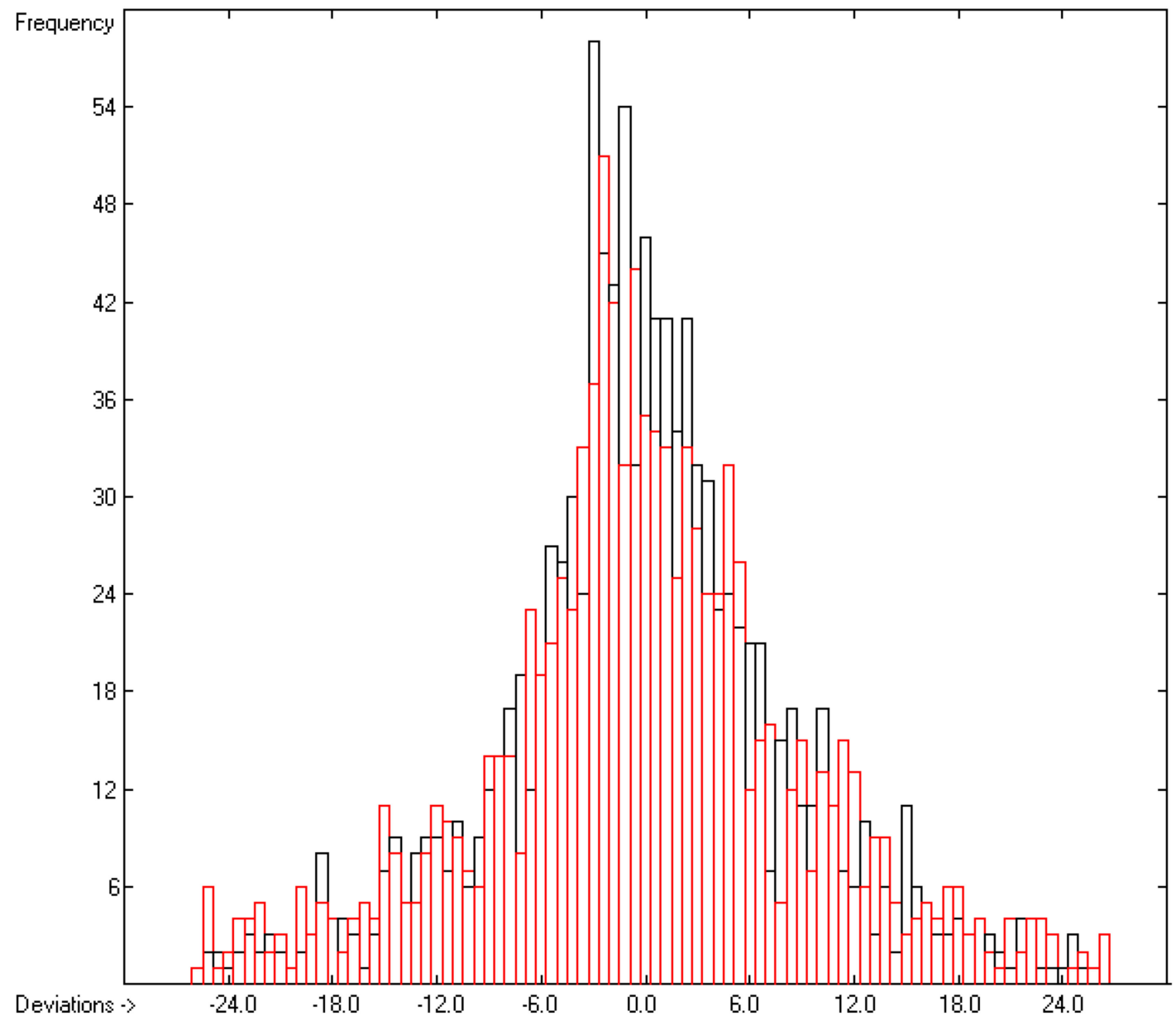

Figure 2. Histogram of the liquid heat-capacity data. The deviations are in $\mathrm{J} / \mathrm{mol} / \mathrm{K}$. The cross-validation data are superimposed as red bars. ( $\mathrm{S}= \pm$ 9.19; Experimental value range: $81.92-1849 \mathrm{~J} / \mathrm{molK}$ ).

Table 4. Experimental $C_{p}($ liq,298) data of 66 alkanols, compared with prediction values calculated by the present the group-additivity (GA) and the $\mathrm{V}_{\mathrm{m}}[1]$ method (in $\mathrm{J} / \mathrm{mol} / \mathrm{K}$ ).

\begin{tabular}{cccccc}
\hline Molecule Name & $\begin{array}{c}\mathbf{C}_{\mathbf{p}}(\mathbf{l i q}, \mathbf{2 9 8}) \\
\text { calc. }(\mathbf{G A})\end{array}$ & Dev. (\%) & $\begin{array}{c}\mathbf{C}_{\mathbf{p}}(\mathbf{l i q}, \mathbf{2 9 8}) \\
\mathbf{e x p} .\end{array}$ & Dev. (\%) & $\begin{array}{c}\mathbf{C}_{\mathbf{p}}(\mathbf{l i q}, \mathbf{2 9 8}) \\
\text { calc. }\end{array}$ \\
\hline 1-Propanol & 155.30 & -5.73 & 146.88 & -8.12 & 158.80 \\
\hline 2-Propanol & 177.70 & -15.07 & 154.43 & -2.83 & 158.80 \\
\hline 2-Methyl-1-propanol & 183.40 & -1.30 & 181.05 & -5.05 & 190.20 \\
\hline 1-Butanol & 185.40 & -4.65 & 177.16 & -7.81 & 191.00 \\
\hline Cyclopentanol & 204.20 & -10.14 & 185.40 & -9.76 & 203.50 \\
\hline 2-Butanol & 207.70 & -5.61 & 196.67 & 3.34 & 190.10 \\
\hline Isopentyl alcohol & 213.50 & -1.86 & 209.60 & -5.92 & 222.00 \\
\hline 1-Pentanol & 215.40 & -3.49 & 208.14 & -7.19 & 223.10 \\
\hline 2-Methyl-2-propanol & 226.50 & -3.61 & 218.60 & 12.76 & 190.70 \\
\hline Cyclohexanol & 230.40 & -7.97 & 213.40 & -9.89 & 234.50 \\
\hline 3-Methyl-2-butanol & 235.80 & 4.11 & 245.90 & 9.68 & 222.10 \\
\hline Cyclohexanemethanol & 236.10 & 0.17 & 236.50 & -12.05 & 265.00 \\
\hline 3,3-Dimethyl-1-butanol & 237.10 & -0.43 & 236.08 & -7.51 & 253.80 \\
\hline
\end{tabular}


Table 4. Cont

\begin{tabular}{|c|c|c|c|c|c|}
\hline Molecule Name & $\begin{array}{l}\mathrm{C}_{\mathrm{p}}(\mathrm{liq}, 298) \\
\text { calc. (GA) }\end{array}$ & Dev. $(\%)$ & $\begin{array}{c}\mathrm{C}_{\mathrm{p}}(\mathrm{liq}, 298) \\
\text { exp. }\end{array}$ & Dev. $(\%)$ & $\begin{array}{l}\mathrm{C}_{\mathrm{p}}(\mathrm{liq}, 298) \\
\text { calc. }\left(\mathrm{V}_{\mathrm{m}}\right)\end{array}$ \\
\hline 3-Pentanol & 237.80 & 0.79 & 239.70 & 6.76 & 223.50 \\
\hline 2-Ethyl-1-butanol & 243.50 & 1.28 & 246.65 & -2.74 & 253.40 \\
\hline 2-Methyl-1-pentanol & 243.50 & 1.97 & 248.40 & -2.62 & 254.90 \\
\hline 1-Hexanol & 245.50 & -1.15 & 242.70 & -5.44 & 255.90 \\
\hline Cycloheptanol & 256.50 & -2.51 & 250.22 & -6.03 & 265.30 \\
\hline 2-Methyl-2-butanol & 256.60 & -3.76 & 247.30 & 10.31 & 221.80 \\
\hline trans-2-Methylcyclohexanol & 258.50 & 1.70 & 262.98 & -1.30 & 266.40 \\
\hline cis-2-Methylcyclohexanol & 258.50 & 3.89 & 268.95 & 1.51 & 264.90 \\
\hline 4-Methyl-2-pentanol & 265.90 & 2.36 & 272.34 & 6.66 & 254.20 \\
\hline 3-Methyl-2-pentanol & 265.90 & 3.62 & 275.89 & 7.93 & 254.00 \\
\hline Cyclohexaneethanol & 266.20 & -0.08 & 266.00 & -12.03 & 298.00 \\
\hline 2-Hexanol & 267.90 & -4.52 & 256.31 & 0.20 & 255.80 \\
\hline 3-Hexanol & 267.90 & 0.51 & 269.27 & 5.49 & 254.50 \\
\hline 1-Heptanol & 275.50 & -0.25 & 274.81 & -4.84 & 288.10 \\
\hline 1-Methylcyclohexanol & 279.20 & -0.05 & 279.05 & 5.03 & 265.00 \\
\hline 2-Methyl-2-pentanol & 286.70 & 0.81 & 289.03 & 11.84 & 254.80 \\
\hline 3-Methyl-3-pentanol & 286.70 & 2.25 & 293.30 & 13.57 & 253.50 \\
\hline 2,4-Dimethyl-3-pentanol & 294.00 & 5.77 & 312.00 & 8.53 & 285.40 \\
\hline 5-Methyl-2-hexanol & 296.00 & -0.27 & 295.20 & 2.74 & 287.10 \\
\hline Cyclohexanepropanol & 296.20 & -1.09 & 293.00 & -12.70 & 330.20 \\
\hline 2-Heptanol & 297.90 & 0.24 & 298.63 & 3.59 & 287.90 \\
\hline 3-Heptanol & 297.90 & 5.19 & 314.20 & 8.37 & 287.90 \\
\hline 4-Heptanol & 297.90 & 2.89 & 306.77 & 6.15 & 287.90 \\
\hline 2-Ethyl-1-hexanol & 303.60 & 4.38 & 317.50 & -0.28 & 318.40 \\
\hline 2-Methyl-1-heptanol & 303.60 & 3.00 & 313.00 & -2.01 & 319.30 \\
\hline 5-Methyl-1-heptanol & 303.60 & 0.20 & 304.20 & -4.73 & 318.60 \\
\hline 1-Octanol & 305.60 & 2.08 & 312.10 & -2.40 & 319.60 \\
\hline 2-Methyl-2-hexanol & 316.70 & -1.01 & 313.54 & 8.50 & 286.90 \\
\hline 2,5-Dimethyl-3-hexanol & 324.00 & 4.54 & 339.40 & 6.25 & 318.20 \\
\hline 2-Methyl-4-heptanol & 326.00 & 1.75 & 331.80 & 4.01 & 318.50 \\
\hline 4-Methyl-2-heptanol & 326.00 & -4.32 & 312.50 & -1.70 & 317.80 \\
\hline 4-Methyl-3-heptanol & 326.00 & -5.43 & 309.20 & -2.81 & 317.90 \\
\hline 6-Methyl-2-heptanol & 326.00 & -3.46 & 315.10 & -1.30 & 319.20 \\
\hline 6-Methyl-3-heptanol & 326.00 & -4.99 & 310.50 & -2.77 & 319.10 \\
\hline 2-Octanol & 328.00 & 0.64 & 330.10 & 3.00 & 320.20 \\
\hline 3-Octanol & 328.00 & 3.10 & 338.50 & 5.44 & 320.10 \\
\hline 4-Octanol & 328.00 & 1.23 & 332.09 & 3.64 & 320.00 \\
\hline 1-Nonanol & 335.70 & 1.55 & 341.00 & -3.37 & 352.50 \\
\hline 2-Methyl-2-heptanol & 346.80 & -2.73 & 337.60 & 5.45 & 319.20 \\
\hline
\end{tabular}


Table 4. Cont.

\begin{tabular}{cccccc}
\hline Molecule Name & $\begin{array}{c}\mathbf{C}_{\mathbf{p}}(\mathbf{l i q}, \mathbf{2 9 8}) \\
\text { calc. (GA) }\end{array}$ & Dev. (\%) & $\begin{array}{c}\mathbf{C}_{\mathbf{p}} \text { (liq, 298) } \\
\text { exp. }\end{array}$ & Dev. (\%) & $\begin{array}{c}\mathbf{C}_{\mathbf{p}}(\mathbf{l i q}, \mathbf{2 9 8}) \\
\text { calc. }\left(\mathbf{V}_{\mathbf{m}}\right)\end{array}$ \\
\hline 4-Methyl-4-heptanol & 346.80 & 5.48 & 366.90 & 13.25 & 318.30 \\
\hline 2-Nonanol & 358.00 & -0.47 & 356.32 & 1.10 & 352.40 \\
\hline 3-Nonanol & 358.00 & 4.18 & 373.63 & 5.71 & 352.30 \\
\hline 4-Nonanol & 358.00 & 2.68 & 367.86 & 4.26 & 352.20 \\
\hline 5-Nonanol & 358.00 & 3.44 & 370.75 & 4.98 & 352.30 \\
\hline 3,7-Dimethyl-1-octanol & 361.80 & 1.47 & 367.21 & -4.05 & 382.10 \\
\hline n-Decyl alcohol & 365.70 & 3.00 & 377.00 & -1.83 & 383.90 \\
\hline 5-Decanol & 388.10 & 4.35 & 405.77 & 5.24 & 384.50 \\
\hline 1-Undecanol & 395.80 & 2.59 & 406.34 & -2.60 & 416.90 \\
\hline 1-Dodecanol & 425.80 & 2.88 & 438.42 & -2.44 & 449.10 \\
\hline 1-Tridecanol & 455.90 & 4.22 & 476.00 & -1.11 & 481.30 \\
\hline Myristyl alcohol & 486.00 & 3.91 & 505.80 & -1.52 & 513.50 \\
\hline 1-Pentadecanol & 516.00 & 3.57 & 535.10 & -1.98 & 545.70 \\
\hline 1-Hexadecanol & 546.10 & -4.26 & 523.80 & -10.33 & 577.90 \\
\hline MAPD & & 3.02 & & 5.51 & \\
\hline & & & & \\
\hline & & & & \\
\hline
\end{tabular}

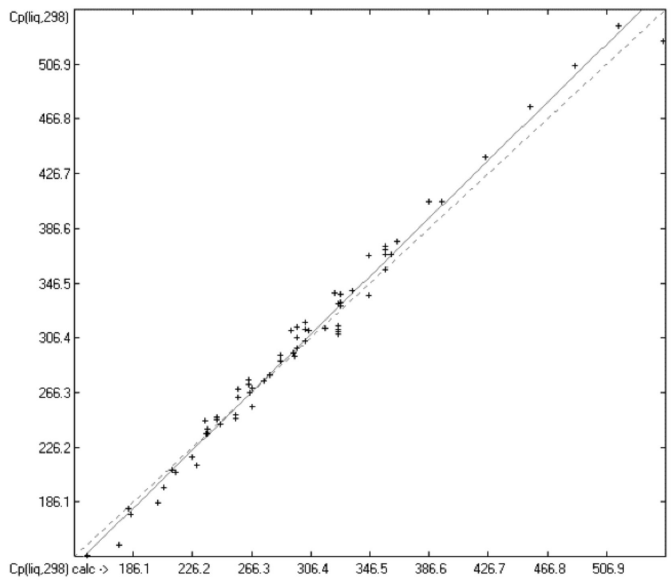

A: GA method

$n=66 ; r^{2}=0.9851 ; s= \pm 9.86 \mathrm{~J} / \mathrm{mol} / \mathrm{K}$

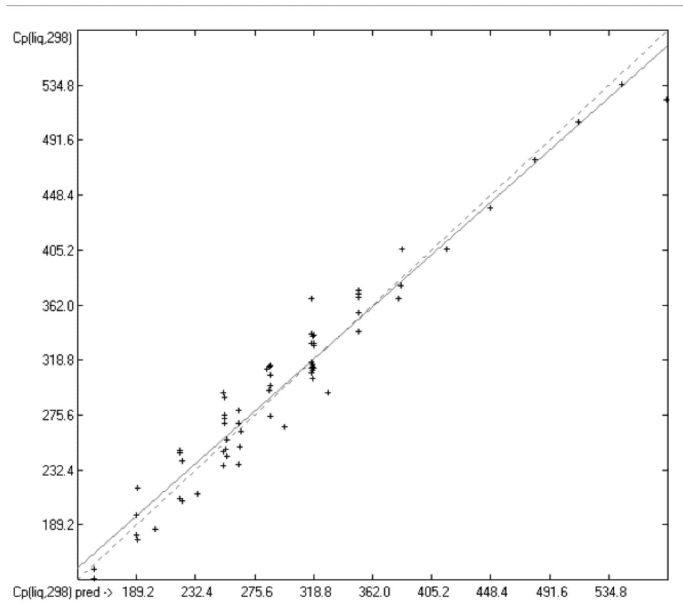

B: $V_{m}$ method [1]

$n=66 ; r^{2}=0.9465 ; s= \pm 18.67 \mathrm{~J} / \mathrm{mol} / \mathrm{K}$

Figure 3. Correlation diagrams of the calculated vs. experimental $C_{p}($ liq,298) data of saturated alcohols (in $\mathrm{J} / \mathrm{mol} / \mathrm{K}$ ) based on $\mathrm{A}$ : the present $\mathrm{GA}$; B: the $\mathrm{V}_{\mathrm{m}}$ method.

A quick review of the contributions of the corresponding atom groups representing the primary, secondary, and tertiary alcohols (group numbers 166 to 168) in Table 3 reveals the large influence of the immediate neighbourhood of the $\mathrm{OH}$ group. Evidently, with its growing bulkiness, the contribution to the heat capacity of the $\mathrm{OH}$ group increases due to its progressively hampered accessibility to build a hydrogen bridge. This effect has been plausibly explained by Huelsekopf and Ludwig [54], who discovered, upon applying theoretical calculations based on the quantum cluster equilibrium theory (QCE) on two primary (ethanol and benzyl alcohol) and a tertiary alcohol (2,2-dimethyl-3-ethyl-3-pentanol), that primary alcohols on principle form cyclic tetramers and pentamers in the liquid phase, while tertiary alcohols under the same conditions only consist of 
monomers and dimers. Following this reasoning, the higher liquid heat capacity of secondary and tertiary alcohols over that of their primary counterparts having the same molecular formula is the result of their formation of smaller clusters, which inherently exhibit a higher number of rotational and translational degrees of freedom.

The third reason for the good compliance of the present $C_{p}$ predictions with experimental values is the consideration of the cyclization effect in the present GA method. Table 5 presents a selection of some linear alkanes and their closely related cycloalkanes and compares their experimental $C_{p}(l i q)$ values with predicted data calculated by means of the present GA method and the $V_{m}$ [1] approach. Scanning the table's fifth column immediately reveals that the $V_{m}$ approach systematically overestimates the liquid heat capacity of the cycloalkanes, whereas those of the linear alkanes are excellently well predicted. The reason is obvious: cyclization reduces the number of rotational degrees of freedom, an effect which is categorically excluded from consideration by the $V_{m}$ method. The present GA method, however, includes this effect in that the number of endocyclic single bonds is counted and their count is multiplied by the assigned special group contribution, in this case by the value of $-3.92 \mathrm{~J} / \mathrm{mol} / \mathrm{K}$ of group 212 in Table 3. The result of this inclusion is evident in column 3 of Table 5, proving that the overestimation of the $C_{p}($ liq) values of the cycloalkanes on average is completely lifted.

Table 5. Experimental $C_{p}($ liq,298) data of four linear alkanes and four related cycloalkanes, compared with the prediction values calculated by the present GA and the $V_{m}[1]$ method (in $\mathrm{J} / \mathrm{mol} / \mathrm{K}$ ).

\begin{tabular}{cccccc}
\hline $\begin{array}{c}\text { Molecule } \\
\text { Name }\end{array}$ & $\begin{array}{c}\mathbf{C}_{\mathbf{p}}(\mathbf{l i q}, \mathbf{2 9 8}) \\
\text { calc. (GA) }\end{array}$ & Dev. (\%) & $\begin{array}{c}\mathrm{C}_{\mathbf{p}}(\mathbf{l i q}, \mathbf{2 9 8}) \\
\text { Exp. }\end{array}$ & Dev. (\%) & $\begin{array}{c}\mathbf{C}_{\mathbf{p}}(\mathbf{l i q}, \mathbf{2 9 8 )} \\
\left.\text { Calc.(V }_{\mathbf{m}}\right)\end{array}$ \\
\hline Cyclopentane & 130.70 & -1.48 & 128.80 & -15.30 & 148.50 \\
\hline Pentane & 164.30 & 1.73 & 167.19 & -0.01 & 167.20 \\
\hline Cyclohexane & 156.80 & 0.82 & 158.10 & -12.14 & 177.30 \\
\hline Hexane & 194.30 & 1.70 & 197.66 & 0.08 & 197.50 \\
\hline Cycloheptane & 183.00 & -1.32 & 180.61 & -13.23 & 204.50 \\
\hline Heptane & 224.40 & 0.41 & 225.33 & -1.10 & 227.80 \\
\hline Cyclooctane & 209.10 & 2.98 & 215.53 & -10.29 & 237.70 \\
\hline Octane & 254.40 & 0.50 & 255.68 & -0.99 & 258.20 \\
\hline
\end{tabular}

An exemplary implementation of these findings may be provided in the calculation according to Equation 1 of the $C_{p}($ liq,298) value of a cyclic alcohol, such as cyclohexanemethanol:

$5 \times[\mathrm{C} \mathrm{sp} 3 / \mathrm{H} 2 \mathrm{C} 2]+[\mathrm{C} \mathrm{sp} 3 / \mathrm{HC} 3]+[\mathrm{C} \mathrm{sp} 3 / \mathrm{H} 2 \mathrm{CO}]+[\mathrm{O}($ prim $) / \mathrm{HC}]+6 \times[$ endocyclic bonds $]=5 \times$ $30.06+21.11+73.79+14.41+6 \times(-3.92)=236.09 \mathrm{~J} / \mathrm{mol} / \mathrm{K}($ experiment: $236.5 \mathrm{~J} / \mathrm{mol} / \mathrm{K})$.

In this context, it is worth mentioning that Chickos et al. [5] took great care about the parametrization of the "cyclic tertiary sp ${ }^{3}$ carbons" (as they called them) and their neighbourhood, but only reserved a single atom group for all the alcohol classes including phenols.

Since, in recent years, the class of ionic liquids (IL) has received increasing interest as a group of new polar solvents, their heat capacity as an important property has come into focus. It was therefore interesting to examine how well the present GA method would cope in comparison with the $V_{m}$ method of [1]. In Table 6, the experimental $C_{p}($ liq,298) data of 122 ILs have been collected and compared to the prediction data calculated by the present GA method and by the $V_{m}$ method. A comparison of the MAPD values at the bottom of the table clearly demonstrate a substantial improvement of the present GA approach over the $V_{m}$ method. 
Table 6. Experimental $C_{\mathrm{p}}($ liq,298) data of 122 ionic liquids, compared with prediction values calculated by the present GA and the $\mathrm{V}_{\mathrm{m}}[1]$ method (in $\mathrm{J} / \mathrm{mol} / \mathrm{K}$ ).

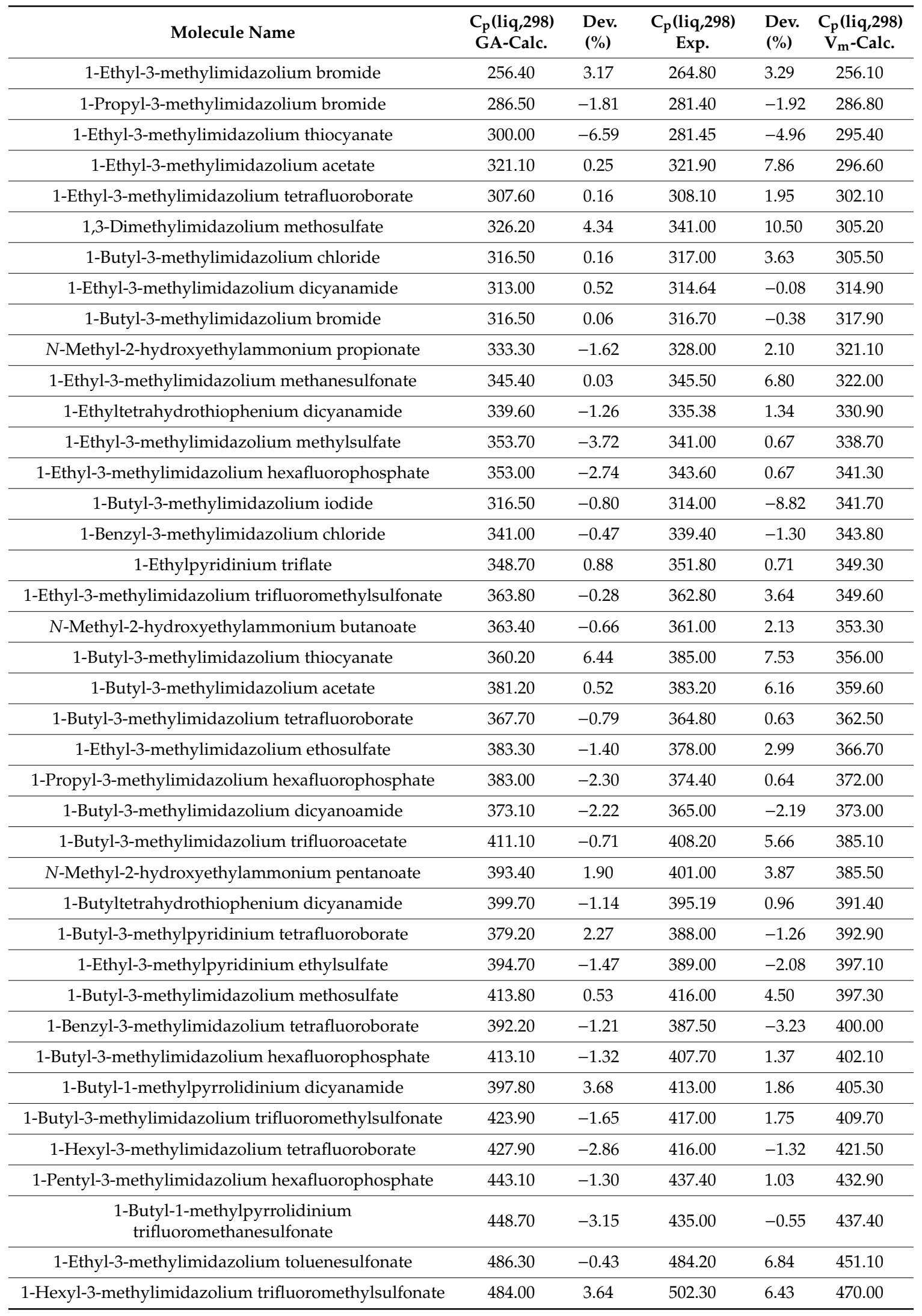


Table 6. Cont

\begin{tabular}{|c|c|c|c|c|c|}
\hline Molecule Name & $\begin{array}{l}\text { Cp }(\text { liq,298) } \\
\text { GA-Calc. }\end{array}$ & $\begin{array}{l}\text { Dev. } \\
(\%)\end{array}$ & $\begin{array}{l}C_{p}(\text { liq,298) } \\
\text { Exp. }\end{array}$ & $\begin{array}{l}\text { Dev. } \\
(\%)\end{array}$ & $\begin{array}{l}\mathrm{C}_{\mathrm{p}}(\mathrm{liq}, 298) \\
\mathrm{V}_{\mathrm{m}} \text {-Calc. }\end{array}$ \\
\hline 1-Octyl-3-methylimidazolium tetrafluoroborate & 488.00 & 2.01 & 498.00 & 2.99 & 483.10 \\
\hline $\begin{array}{l}\text { 1-Ethyl-3-methylimidazolium } \\
\text { bis(trifluoromethanesulfonyl) amide }\end{array}$ & 506.70 & -1.34 & 500.00 & 3.36 & 483.20 \\
\hline N-Ethylpyridinium bis(trifluoromethylsulfonyl)amide & 491.50 & 2.12 & 502.15 & 2.98 & 487.20 \\
\hline $\begin{array}{l}\text { 1-Ethyl-3-methylimidazolium } \\
\text { 2-(2-methoxyethoxy)ethylsulfate }\end{array}$ & 530.50 & -0.86 & 526.00 & 6.29 & 492.90 \\
\hline 1-Heptyl-3-methylimidazolium hexafluorophosphate & 503.30 & -0.54 & 500.60 & 1.34 & 493.90 \\
\hline $\begin{array}{l}\text { 1-Isopropyl-3-methylimidazolium } \\
\text { bis(trifluoromethanesulfonyl) amide }\end{array}$ & 535.20 & -1.00 & 529.90 & 3.25 & 512.70 \\
\hline $\begin{array}{l}\text { 1-Propyl-3-methylimidazolium } \\
\text { bis(trifluoromethanesulfonyl) amide }\end{array}$ & 536.70 & -0.34 & 534.90 & 4.08 & 513.10 \\
\hline 1-Butyl-3-methylimidazolium toluenesulfonate & 546.40 & 0.36 & 548.40 & 6.20 & 514.40 \\
\hline $\begin{array}{l}N \text {-Ethyl-2-methylpyridinium } \\
\text { bis(trifluoromethylsulfonyl)amide }\end{array}$ & 535.30 & -0.15 & 534.50 & 3.55 & 515.50 \\
\hline 1-Octyl-3-methylimidazolium hexafluorophosphate & 533.30 & 0.52 & 536.10 & 2.16 & 524.50 \\
\hline $\begin{array}{l}\text { 1-Cyclopropylmethyl-3-methylimidazolium } \\
\text { bis(trifluoromethanesulfonyl) amide }\end{array}$ & 551.50 & -2.30 & 539.10 & 1.21 & 532.60 \\
\hline $\begin{array}{l}\text { Trimethyl butylammonium } \\
\text { bis(trifluoromethylsulfonyl)amide }\end{array}$ & 561.10 & -0.34 & 559.20 & 4.02 & 536.70 \\
\hline $\begin{array}{l}\text { 1,2-Diethylpyridinium bis(trifluoromethanesulfonyl) } \\
\text { amide }\end{array}$ & 565.40 & 0.12 & 566.10 & 4.82 & 538.80 \\
\hline $\begin{array}{l}\text { 1-Butyl-3-methylimidazolium } \\
\text { bis(trifluoromethanesulfonyl) amide }\end{array}$ & 566.80 & -0.16 & 565.90 & 4.22 & 542.00 \\
\hline $\begin{array}{l}\text { 1-sec-Butyl-3-methylimidazolium } \\
\text { bis(trifluoromethanesulfonyl) amide }\end{array}$ & 565.30 & -1.47 & 557.10 & 2.64 & 542.40 \\
\hline $\begin{array}{l}\text { 1-Methyl-1-propylpyrrolidinium } \\
\text { bis(trifluoromethanesulfonyl) amide }\end{array}$ & 561.50 & -1.35 & 554.00 & 1.93 & 543.30 \\
\hline $\begin{array}{l}\text { 1-Isobutyl-3-methylimidazolium } \\
\text { bis(trifluoromethanesulfonyl) amide }\end{array}$ & 564.80 & -1.38 & 557.10 & 2.48 & 543.30 \\
\hline $\begin{array}{l}N \text {-Propyl-2-methylpyridinium } \\
\text { bis(trifluoromethylsulfonyl)amide }\end{array}$ & 565.40 & -1.33 & 557.96 & 2.18 & 545.80 \\
\hline N-Butylpyridinium bis(trifluoromethanesulfonyl) amide & 551.60 & 2.63 & 566.52 & 3.50 & 546.70 \\
\hline 1-Nonyl-3-methylimidazolium hexafluorophosphate & 563.40 & 1.05 & 569.40 & 2.79 & 553.50 \\
\hline $\mathrm{N}$-Octylisoquinolinium thiocyanate & 528.30 & -1.21 & 522.00 & -6.88 & 557.90 \\
\hline $\begin{array}{l}\text { 1-Butyltetrahydrothiophenium } \\
\text { bis(trifluoromethylsulfonyl) amide }\end{array}$ & 593.40 & 0.44 & 596.00 & 6.12 & 559.50 \\
\hline $\begin{array}{l}N \text {-Ethyl-4-dimethylaminopyridinium } \\
\text { bis(trifluoromethanesulfonyl) amide }\end{array}$ & 591.20 & 0.52 & 594.30 & 4.37 & 568.30 \\
\hline $\begin{array}{l}\text { 1-Pentyl-3-methylimidazolium } \\
\text { bis(trifluoromethanesulfonyl) amide }\end{array}$ & 596.90 & -0.22 & 595.60 & 4.08 & 571.30 \\
\hline $\begin{array}{l}\text { 1-Ethyl-2-propylpyridinium } \\
\text { bis(trifluoromethanesulfonyl) amide }\end{array}$ & 595.40 & -0.25 & 593.90 & 3.25 & 574.60 \\
\hline $\begin{array}{l}\text { 1-Isobutyl-1-methylpyrrolidinium } \\
\text { bis(trifluoromethylsulfonyl)amide }\end{array}$ & 589.60 & -1.27 & 582.20 & 1.03 & 576.20 \\
\hline $\begin{array}{l}\text { 1-Isobutyl-3-methylpyridinium } \\
\text { bis(trifluoromethylsulfonyl)amide }\end{array}$ & 576.30 & 0.47 & 579.00 & 0.40 & 576.70 \\
\hline $\begin{array}{l}N \text {-Butyl-3-methylpyridinium } \\
\text { bis(trifluoromethylsulfonyl)amide }\end{array}$ & 578.20 & -0.02 & 578.10 & 0.14 & 577.30 \\
\hline
\end{tabular}


Table 6. Cont

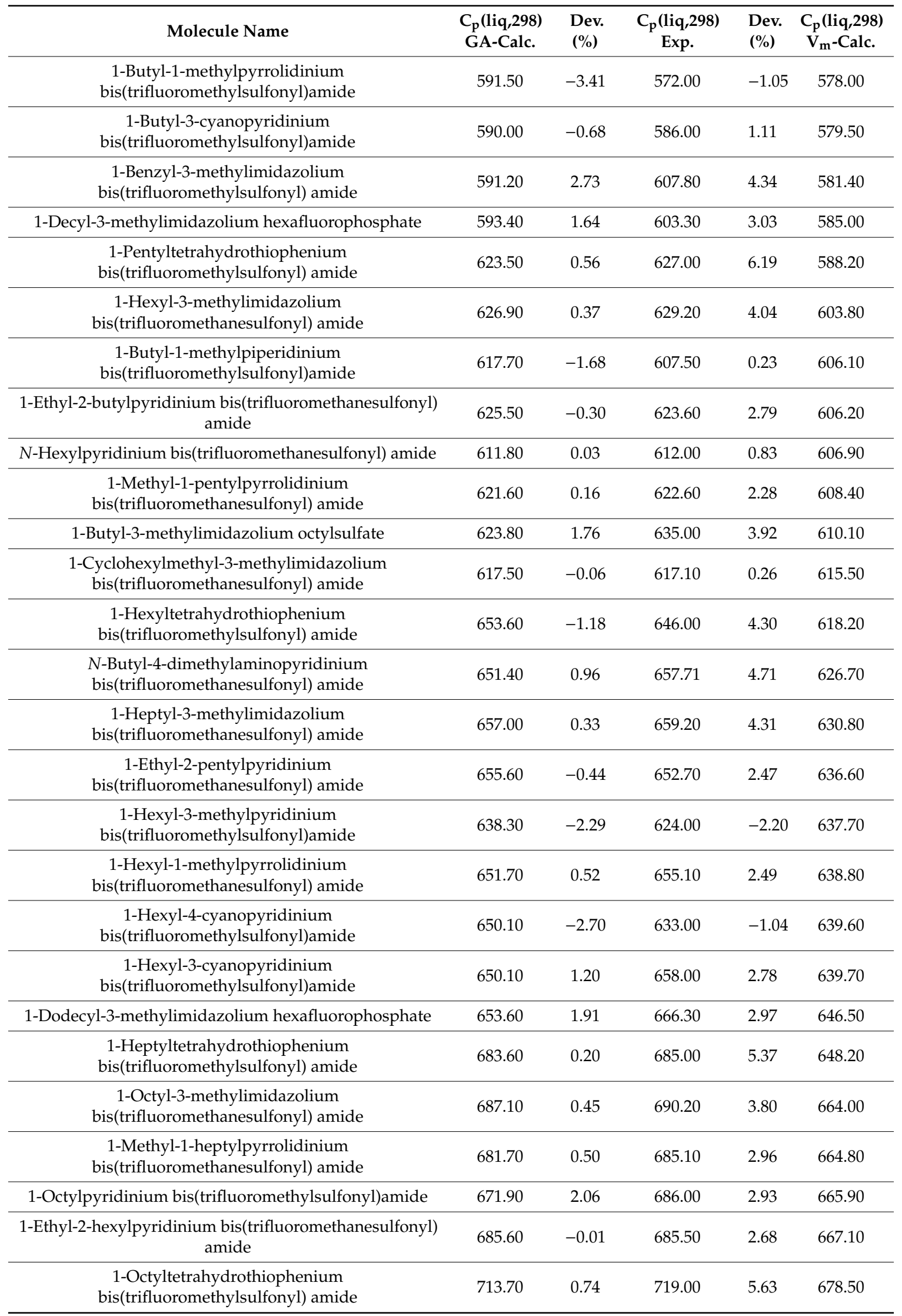


Table 6. Cont

\begin{tabular}{|c|c|c|c|c|c|}
\hline Molecule Name & $\begin{array}{l}\mathrm{C}_{\mathrm{p}}(\mathrm{liq}, 298) \\
\text { GA-Calc. }\end{array}$ & $\begin{array}{l}\text { Dev. } \\
(\%)\end{array}$ & $\begin{array}{l}\mathrm{C}_{\mathrm{p}}(\mathrm{liq}, 298) \\
\text { Exp. }\end{array}$ & $\begin{array}{l}\text { Dev. } \\
(\%)\end{array}$ & $\begin{array}{l}\mathrm{C}_{\mathrm{p}}(\mathrm{liq}, 298) \\
\mathrm{V}_{\mathrm{m}} \text {-Calc. }\end{array}$ \\
\hline $\begin{array}{l}\text { 1-(3,4,5,6-Perfluorohexyl)-3-methylimidazolium-3- } \\
\text { methylimidazolium bis(trifluoromethanesulfonyl) amide }\end{array}$ & 719.30 & 0.79 & 725.00 & 6.40 & 678.60 \\
\hline $\begin{array}{l}\text { 4-Dimethylamino-1-hexylpyridinium } \\
\text { bis(trifluoromethanesulfonyl) amide }\end{array}$ & 711.50 & 2.67 & 731.00 & 5.99 & 687.20 \\
\hline $\begin{array}{l}\text { 1-Ethyl-2-heptylpyridinium } \\
\text { bis(trifluoromethanesulfonyl) amide }\end{array}$ & 715.70 & 0.25 & 717.50 & 2.80 & 697.40 \\
\hline $\begin{array}{l}\text { 1-Methyl-1-octylpyrrolidinium } \\
\text { bis(trifluoromethanesulfonyl) amide }\end{array}$ & 711.80 & 0.63 & 716.30 & 2.36 & 699.40 \\
\hline $\begin{array}{l}\text { 1-Octyl-3-cyanopyridinium } \\
\text { bis(trifluoromethylsulfonyl)amide }\end{array}$ & 710.20 & -0.17 & 709.00 & 1.26 & 700.10 \\
\hline $\begin{array}{l}\mathrm{N} \text {-Hexyl-3-methyl-4-dimethylaminopyridinium } \\
\text { bis(trifluoromethanesulfonyl) amide }\end{array}$ & 738.10 & -1.81 & 725.00 & 1.94 & 710.90 \\
\hline $\begin{array}{l}\text { 1-Nonyltetrahydrothiophenium } \\
\text { bis(trifluoromethylsulfonyl) amide }\end{array}$ & 743.70 & -0.36 & 741.00 & 4.01 & 711.30 \\
\hline $\begin{array}{l}\text { Butyl 1-butylnicotinate } \\
\text { bis(trifluoromethylsulfonyl)amide }\end{array}$ & 728.90 & -3.10 & 707.00 & -0.91 & 713.40 \\
\hline $\begin{array}{l}\text { 1-Decyl-3-methylimidazolium } \\
\text { bis(trifluoromethanesulfonyl) amide }\end{array}$ & 747.20 & 1.01 & 754.80 & 4.03 & 724.40 \\
\hline $\begin{array}{l}\text { 1-Ethyl-2-octylpyridinium bis(trifluoromethanesulfonyl) } \\
\text { amide }\end{array}$ & 745.70 & 0.49 & 749.40 & 3.26 & 725.00 \\
\hline $\begin{array}{l}\text { 1-Methyl-3-menthyloxymethylimidazolium } \\
\text { bis(trifluoromethylsulfonyl)imide }\end{array}$ & 785.90 & -0.58 & 781.40 & 4.20 & 748.60 \\
\hline $\begin{array}{l}\text { 1-Ethyl-2-nonylpyridinium bis(trifluoromethanesulfonyl) } \\
\text { amide }\end{array}$ & 775.80 & 0.35 & 778.50 & 3.48 & 751.40 \\
\hline $\begin{array}{l}\text { 1-Methyl-1-decylpyrrolidinium } \\
\text { bis(trifluoromethanesulfonyl) amide }\end{array}$ & 771.90 & 0.90 & 778.90 & 2.40 & 760.20 \\
\hline $\begin{array}{l}\text { 1-Ethyl-3-menthyloxymethylimidazolium } \\
\text { bis(trifluoromethylsulfonyl)imide }\end{array}$ & 813.40 & 0.61 & 818.40 & 4.55 & 781.20 \\
\hline $\begin{array}{l}\text { 1-Dodecyl-3-methylimidazolium } \\
\text { bis(trifluoromethanesulfonyl) amide }\end{array}$ & 807.30 & 1.57 & 820.20 & 4.04 & 787.10 \\
\hline $\begin{array}{l}\text { 1-Ethyl-2-decylpyridinium bis(trifluoromethanesulfonyl) } \\
\text { amide }\end{array}$ & 805.80 & 0.67 & 811.20 & 2.79 & 788.60 \\
\hline $\begin{array}{l}\text { 1-Propyl-3-menthyloxymethylimidazolium } \\
\text { bis(trifluoromethylsulfonyl)imide }\end{array}$ & 843.50 & -0.49 & 839.40 & 3.71 & 808.30 \\
\hline $\begin{array}{l}\text { 1-Butyl-3-menthyloxymethylimidazolium } \\
\text { bis(trifluoromethylsulfonyl)imide }\end{array}$ & 873.50 & -0.84 & 866.20 & 3.20 & 838.50 \\
\hline $\begin{array}{l}\text { 1-Pentyl-3-menthyloxymethylimidazolium } \\
\text { bis(trifluoromethylsulfonyl)imide }\end{array}$ & 903.60 & 0.15 & 905.00 & 3.55 & 872.90 \\
\hline $\begin{array}{l}\text { 1-Hexyl-3-menthyloxymethylimidazolium } \\
\text { bis(trifluoromethylsulfonyl)imide }\end{array}$ & 933.70 & 1.15 & 944.60 & 4.74 & 899.80 \\
\hline $\begin{array}{l}\text { 1-Heptyl-3-menthyloxymethylimidazolium } \\
\text { bis(trifluoromethylsulfonyl)imide }\end{array}$ & 963.70 & -0.33 & 960.50 & 3.25 & 929.30 \\
\hline $\begin{array}{l}\text { 1-Octyl-3-menthyloxymethylimidazolium } \\
\text { bis(trifluoromethylsulfonyl)imide }\end{array}$ & 993.80 & 0.12 & 995.00 & 3.59 & 959.30 \\
\hline $\begin{array}{l}\text { 1-Nonyl-3-menthyloxymethylimidazolium } \\
\text { bis(trifluoromethylsulfonyl)imide }\end{array}$ & 1023.80 & -0.02 & 1023.60 & 2.83 & 994.60 \\
\hline $\begin{array}{l}\text { 1-Decyl-3-menthyloxymethylimidazolium } \\
\text { bis(trifluoromethylsulfonyl)imide }\end{array}$ & 1053.90 & -0.76 & 1045.90 & 2.31 & 1021.70 \\
\hline
\end{tabular}


Table 6. Cont.

\begin{tabular}{|c|c|c|c|c|c|}
\hline Molecule Name & $\begin{array}{l}\text { Cp }(\text { liq, 298) } \\
\text { GA-Calc. }\end{array}$ & $\begin{array}{l}\text { Dev. } \\
(\%)\end{array}$ & $\begin{array}{l}\mathrm{C}_{\mathrm{p}}(\mathrm{liq}, 298) \\
\text { Exp. }\end{array}$ & $\begin{array}{l}\text { Dev. } \\
(\%)\end{array}$ & $\begin{array}{l}\mathrm{C}_{\mathrm{p}}(\mathrm{liq}, 298) \\
\mathrm{V}_{\mathrm{m}} \text {-Calc. }\end{array}$ \\
\hline $\begin{array}{l}\text { 1-Undecyl-3-menthyloxymethylimidazolium } \\
\text { bis(trifluoromethylsulfonyl)imide }\end{array}$ & 1084.00 & 0.40 & 1088.30 & 3.55 & 1049.70 \\
\hline $\begin{array}{l}\text { 1-Dodecyl-3-menthyloxymethylimidazolium } \\
\text { bis(trifluoromethylsulfonyl)imide }\end{array}$ & 1114.00 & 0.35 & 1117.90 & 2.85 & 1086.00 \\
\hline $\begin{array}{l}\text { Tetradecyl trihexylphosphonium } \\
\text { bis(trifluoromethylsulfonyl)amide }\end{array}$ & 1312.10 & -1.02 & 1298.80 & -1.35 & 1316.30 \\
\hline MAPD & & 1.13 & & 3.08 & \\
\hline
\end{tabular}

The present calculation of the atom-group parameters for the prediction of $\mathrm{C}_{\mathrm{p}}(\mathrm{liq}, 298)$ revealed ca. 170 compounds with experimental values exceeding the deviation limit, as defined in Section 2, which have been removed from parameters calculations and are collected in an outliers list. A comparison of this list with that resulting from calculations by means of the $V_{m}$ method [1] showed very high overlap, indicating that the exclusion of these compounds was indeed justified. After the removal of these outliers, a limited number of 1202 compounds with usable experimental data remained, supporting the contributions of 134 atom and special groups valid for prediction calculations, as is shown in row A of Table 3. Despite this fairly low number of atom groups, the range of applicability of the present GA method is considerably high: for nearly $62 \%$ of ChemBrain's database of the more than 32000 compounds, the liquid heat capacity has been evaluable.

\subsection{Heat Capacity of Solids}

While the measurement of the heat capacity of liquids principally implies a consistent isotropic phase, the corresponding examination of solids very often faces the question as to what type of association the particular compound has adopted in its solid phase. Many compounds precipitate in various crystalline forms, depending on the precipitation conditions, each of them having a different heat capacity, and many of these can change from one into another crystalline structure upon measurement, perhaps even switching from one tautomeric form into another one. In some cases, the apparent solid is merely a supercooled melt. The uncertainty of the actual structure of the solids appears to be the main cause of the larger scatter of the heat capacities of solids $C_{p}(s o l, 298)$ as compared to that of the liquids, not only over the complete range of available compounds but also over particular compounds examined by several independent sources, as has been observed by Chickos et al. [5]. These uncertainties are expressed in the statistics data at the bottom of Table 7, which presents the list of atom and special groups and their contribution for the prediction of the heat capacity of solids. Based on the $C_{p}$ data of 804 solids, the Gauss-Seidel calculus yielded 126 atom and special groups (row A in Table 7) valid for prediction calculations and a cross-validation standard deviation $q^{2}$ of $14.23 \mathrm{~J} / \mathrm{mol} / \mathrm{K}$ (row $\mathrm{H}$ ). This standard deviation is clearly higher than that for the calculation of the liquid heat capacities, but much lower than the $26.9 \mathrm{~J} / \mathrm{mol} / \mathrm{K}$ of Chickos' method [5] and even lower than the experimental variation of $23.4 \mathrm{~J} / \mathrm{mol} / \mathrm{K}$ for each of the 102 solids originating from independent sources [5]. The MAPD value for the complete set of solids was calculated to $4.74 \%$, which is better than that of each of the subsets of compounds calculated by means of the $V_{m}$ method [1]. Nevertheless, as is demonstrated in the corresponding diagram (Figure 4), the scatter around the correlation line is significantly larger compared to the one of Figure 1 for the liquid heat capacity. Analogously, the histogram (Figure 5) shows a wider "waist" than that of Figure 2. 
Table 7. Atom groups and their contributions for the heat-capacity calculation of solids.

\begin{tabular}{|c|c|c|c|c|c|}
\hline Entry & Atom Type & Neighbours & Contribution & Occurrences & Molecules \\
\hline 1 & $\mathrm{~B}(-)$ & $\mathrm{F} 4$ & 2.99 & 1 & 1 \\
\hline 2 & C sp3 & $\mathrm{H} 3 \mathrm{C}$ & 37.12 & 569 & 246 \\
\hline 3 & C sp3 & $\mathrm{H} 3 \mathrm{~N}$ & 101.28 & 50 & 34 \\
\hline 4 & C sp3 & $\mathrm{H} 3 \mathrm{~N}(+)$ & 99.59 & 7 & 4 \\
\hline 5 & C sp3 & $\mathrm{H} 3 \mathrm{O}$ & 68.06 & 51 & 35 \\
\hline 6 & C sp3 & H3S & 45.85 & 3 & 3 \\
\hline 7 & C sp3 & Н3Р & 131.12 & 1 & 1 \\
\hline 8 & C sp3 & $\mathrm{H} 3 \mathrm{Si}$ & 59.18 & 14 & 5 \\
\hline 9 & C sp3 & $\mathrm{H} 2 \mathrm{C} 2$ & 25.45 & 1427 & 249 \\
\hline 10 & C sp3 & $\mathrm{H} 2 \mathrm{CN}$ & 82.72 & 89 & 56 \\
\hline 11 & C sp3 & $\mathrm{H} 2 \mathrm{CN}(+)$ & 81.35 & 19 & 15 \\
\hline 12 & C sp3 & $\mathrm{H} 2 \mathrm{CO}$ & 64.67 & 210 & 108 \\
\hline 13 & C sp3 & $\mathrm{H} 2 \mathrm{CS}$ & 72.27 & 22 & 12 \\
\hline 14 & C sp3 & $\mathrm{H} 2 \mathrm{CF}$ & 53.68 & 4 & 1 \\
\hline 15 & C sp3 & $\mathrm{H} 2 \mathrm{CCl}$ & 50.12 & 4 & 1 \\
\hline 16 & C sp3 & $\mathrm{H} 2 \mathrm{CBr}$ & 54.73 & 5 & 2 \\
\hline 17 & C sp3 & $\mathrm{H} 2 \mathrm{CJ}$ & 52.94 & 4 & 1 \\
\hline 18 & C sp3 & $\mathrm{H} 2 \mathrm{CSi}$ & 63.12 & 1 & 1 \\
\hline 19 & C sp3 & H2N2 & 134.39 & 13 & 3 \\
\hline 20 & C sp3 & $\mathrm{H} 2 \mathrm{O} 2$ & 108.47 & 12 & 3 \\
\hline 21 & C sp3 & $\mathrm{H} 2 \mathrm{~S} 2$ & -6.67 & 3 & 3 \\
\hline 22 & C sp3 & $\mathrm{HC} 3$ & 11.92 & 164 & 73 \\
\hline 23 & C sp3 & $\mathrm{HC} 2 \mathrm{~N}$ & 72.94 & 28 & 23 \\
\hline 24 & C sp3 & $\mathrm{HC} 2 \mathrm{~N}(+)$ & 70.74 & 29 & 28 \\
\hline 25 & C sp3 & $\mathrm{HC} 2 \mathrm{O}$ & 51.84 & 161 & 63 \\
\hline 26 & C sp3 & $\mathrm{HC} 2 \mathrm{~S}$ & 47.22 & 4 & 2 \\
\hline 27 & C sp3 & $\mathrm{HC} 2 \mathrm{Si}$ & 142.27 & 1 & 1 \\
\hline 28 & C sp3 & HCN2 & 137.04 & 1 & 1 \\
\hline 29 & C sp3 & $\mathrm{HCNO}$ & 119.89 & 7 & 5 \\
\hline 30 & C sp3 & HCNS & 116.08 & 2 & 1 \\
\hline 31 & C sp3 & $\mathrm{HCO} 2$ & 112.62 & 17 & 14 \\
\hline 32 & C sp3 & HCF2 & 246.8 & 1 & 1 \\
\hline 33 & C sp3 & HCBr2 & 68.67 & 1 & 1 \\
\hline 34 & C sp3 & $\mathrm{C} 4$ & -2.17 & 81 & 48 \\
\hline 35 & C sp3 & $\mathrm{C} 3 \mathrm{~N}$ & 62.09 & 11 & 9 \\
\hline 36 & C sp3 & $\mathrm{C} 3 \mathrm{~N}(+)$ & 19.23 & 2 & 2 \\
\hline 37 & C sp3 & $\mathrm{C} 3 \mathrm{O}$ & 27.59 & 10 & 10 \\
\hline 38 & C sp3 & $\mathrm{C} 3 \mathrm{Cl}$ & 78.13 & 1 & 1 \\
\hline 39 & C sp3 & $\mathrm{C} 3 \mathrm{Br}$ & 44.34 & 1 & 1 \\
\hline
\end{tabular}


Table 7. Cont

\begin{tabular}{|c|c|c|c|c|c|}
\hline Entry & Atom Type & Neighbours & Contribution & Occurrences & Molecules \\
\hline 40 & C sp3 & $\mathrm{C} 2 \mathrm{NO}$ & 89.86 & 1 & 1 \\
\hline 41 & C sp3 & $\mathrm{C} 2 \mathrm{O} 2$ & 91.75 & 6 & 5 \\
\hline 42 & C sp3 & $\mathrm{C} 2 \mathrm{~S} 2$ & 43.86 & 5 & 2 \\
\hline 43 & C sp3 & CF3 & 69.89 & 2 & 2 \\
\hline 44 & C sp3 & CSF2 & 0 & 1 & 1 \\
\hline 45 & C sp3 & $\mathrm{CCl} 3$ & 92.28 & 4 & 3 \\
\hline 46 & C sp2 & $\mathrm{H} 2=\mathrm{C}$ & 39.96 & 6 & 6 \\
\hline 47 & C sp2 & $\mathrm{HC}=\mathrm{C}$ & 16.95 & 109 & 65 \\
\hline 48 & C sp2 & $\mathrm{HC}=\mathrm{N}$ & 99.99 & 13 & 13 \\
\hline 49 & C sp2 & $\mathrm{HC}=\mathrm{O}$ & 43.05 & 14 & 12 \\
\hline 50 & C sp2 & $\mathrm{H}=\mathrm{CN}$ & 33.94 & 25 & 17 \\
\hline 51 & C sp2 & $\mathrm{H}=\mathrm{CO}$ & 41.99 & 3 & 3 \\
\hline 52 & C sp2 & $\mathrm{H}=\mathrm{CS}$ & 36.19 & 7 & 5 \\
\hline 53 & C sp2 & $\mathrm{H}=\mathrm{CCl}$ & 19.44 & 1 & 1 \\
\hline 54 & C sp2 & $\mathrm{HN}=\mathrm{N}$ & 102.56 & 17 & 14 \\
\hline 55 & C sp2 & $\mathrm{HN}=\mathrm{O}$ & 28.91 & 4 & 3 \\
\hline 56 & C sp2 & $\mathrm{H}=\mathrm{NO}$ & 112.57 & 1 & 1 \\
\hline 57 & C sp2 & $\mathrm{C} 2=\mathrm{C}$ & 5.77 & 29 & 22 \\
\hline 58 & C sp2 & $\mathrm{C} 2=\mathrm{N}$ & 95.44 & 14 & 10 \\
\hline 59 & C sp2 & $\mathrm{C} 2=\mathrm{N}(+)$ & -9.61 & 2 & 2 \\
\hline 60 & C sp2 & $\mathrm{C}=\mathrm{CN}$ & 18.4 & 16 & 15 \\
\hline 61 & C sp2 & $\mathrm{C} 2=\mathrm{O}$ & 27.68 & 44 & 30 \\
\hline 62 & C sp2 & $\mathrm{C}=\mathrm{CO}$ & 25.28 & 15 & 13 \\
\hline 63 & C sp2 & $\mathrm{C}=\mathrm{CS}$ & 29.08 & 5 & 4 \\
\hline 64 & C sp2 & $\mathrm{C}=\mathrm{CCl}$ & 35.2 & 6 & 3 \\
\hline 65 & C sp2 & $=\mathrm{CN} 2$ & 38.93 & 14 & 14 \\
\hline 66 & C sp2 & $=\mathrm{CN} 2(+)$ & 78.32 & 7 & 7 \\
\hline 67 & C sp2 & $\mathrm{CN}=\mathrm{N}$ & 87.15 & 19 & 13 \\
\hline 68 & C sp2 & $\mathrm{CN}=\mathrm{N}(+)$ & 118.23 & 2 & 1 \\
\hline 69 & C sp2 & $\mathrm{CN}=\mathrm{O}$ & 37.33 & 131 & 92 \\
\hline 70 & C sp2 & $=\mathrm{CNO}$ & 55.09 & 1 & 1 \\
\hline 71 & C sp2 & $\mathrm{CN}=\mathrm{S}$ & 46.51 & 3 & 3 \\
\hline 72 & C sp2 & $\mathrm{CO}=\mathrm{O}$ & 51.25 & 208 & 155 \\
\hline 73 & C sp2 & $\mathrm{CO}=\mathrm{O}(-)$ & 15.25 & 41 & 40 \\
\hline 74 & C sp2 & $\mathrm{C}=\mathrm{OCl}$ & 61.46 & 2 & 1 \\
\hline 75 & C sp2 & $=\mathrm{CS} 2$ & 45.53 & 12 & 2 \\
\hline 76 & C sp2 & $\mathrm{N} 2=\mathrm{N}$ & 113.97 & 5 & 3 \\
\hline 77 & C sp2 & $\mathrm{N} 2=\mathrm{O}$ & 55.72 & 43 & 38 \\
\hline 78 & C sp2 & $\mathrm{N}=\mathrm{NO}$ & 91.56 & 1 & 1 \\
\hline
\end{tabular}


Table 7. Cont

\begin{tabular}{|c|c|c|c|c|c|}
\hline Entry & Atom Type & Neighbours & Contribution & Occurrences & Molecules \\
\hline 79 & C sp2 & $\mathrm{N} 2=\mathrm{S}$ & 67.02 & 7 & 7 \\
\hline 80 & C sp2 & $\mathrm{N}=\mathrm{NS}$ & 105.95 & 7 & 7 \\
\hline 81 & C sp2 & $\mathrm{NO}=\mathrm{O}$ & 63.43 & 8 & 8 \\
\hline 82 & C sp2 & $\mathrm{NO}=\mathrm{S}$ & 64.85 & 3 & 3 \\
\hline 83 & C sp2 & $=\mathrm{NOS}$ & 108.01 & 1 & 1 \\
\hline 84 & C sp2 & $\mathrm{NS}=\mathrm{S}$ & 62.46 & 4 & 3 \\
\hline 85 & C sp2 & $\mathrm{O} 2=\mathrm{O}$ & 58.47 & 5 & 5 \\
\hline 86 & C sp2 & $\mathrm{OS}=\mathrm{S}$ & 63.23 & 1 & 1 \\
\hline 87 & $\mathrm{C}$ aromatic & $\mathrm{H}: \mathrm{C} 2$ & 17.96 & 3232 & 437 \\
\hline 88 & $\mathrm{C}$ aromatic & $\mathrm{H}: \mathrm{C}: \mathrm{N}$ & 24.16 & 37 & 20 \\
\hline 89 & $\mathrm{C}$ aromatic & $\mathrm{H}: \mathrm{C}: \mathrm{N}(+)$ & 21.47 & 2 & 1 \\
\hline 90 & $\mathrm{C}$ aromatic & H:N2 & 7.08 & 3 & 3 \\
\hline 91 & $\mathrm{C}$ aromatic & :C3 & 8.04 & 171 & 57 \\
\hline 92 & $\mathrm{C}$ aromatic & $\mathrm{C}: \mathrm{C} 2$ & 6.56 & 699 & 307 \\
\hline 93 & $\mathrm{C}$ aromatic & $C: C: N$ & 5.85 & 13 & 9 \\
\hline 94 & $\mathrm{C}$ aromatic & :C2N & 24.29 & 172 & 107 \\
\hline 95 & $\mathrm{C}$ aromatic & $: \mathrm{C} 2 \mathrm{~N}(+)$ & 49.48 & 57 & 42 \\
\hline 96 & $\mathrm{C}$ aromatic & $: \mathrm{C} 2: \mathrm{N}$ & 19.63 & 13 & 7 \\
\hline 97 & $\mathrm{C}$ aromatic & :C2O & 29.21 & 184 & 113 \\
\hline 98 & C aromatic & :C2P & 15.1 & 6 & 2 \\
\hline 99 & C aromatic & :C2S & 27.43 & 43 & 28 \\
\hline 100 & $\mathrm{C}$ aromatic & :C2Si & 58.51 & 53 & 12 \\
\hline 101 & $\mathrm{C}$ aromatic & :C2F & 31.08 & 25 & 9 \\
\hline 102 & $\mathrm{C}$ aromatic & $\mathrm{C} 2 \mathrm{Cl}$ & 34.35 & 57 & 25 \\
\hline 103 & C aromatic & :C2Br & 37.48 & 18 & 9 \\
\hline 104 & $\mathrm{C}$ aromatic & :C2J & 48.49 & 5 & 3 \\
\hline 105 & $\mathrm{C}$ aromatic & $\mathrm{C}: \mathrm{N} 2$ & 18.81 & 3 & 1 \\
\hline 106 & $\mathrm{C}$ aromatic & :CN:N & 39.03 & 7 & 5 \\
\hline 107 & $\mathrm{C}$ aromatic & :C:NO & 53.92 & 1 & 1 \\
\hline 108 & $\mathrm{C}$ aromatic & :C:NCl & 49.04 & 3 & 3 \\
\hline 109 & C aromatic & $\mathrm{N}: \mathrm{N} 2$ & 36.22 & 4 & 2 \\
\hline 110 & $\mathrm{C}$ aromatic & :N2O & 40.81 & 3 & 1 \\
\hline 111 & $\mathrm{C}(+)$ aromatic & $\mathrm{H}: \mathrm{N} 2$ & -39.63 & 3 & 3 \\
\hline 112 & $\mathrm{C}(+)$ aromatic & :N3 & -20.94 & 2 & 2 \\
\hline 113 & C sp & $\mathrm{H \# C}$ & 103.03 & 2 & 1 \\
\hline 114 & C sp & $\mathrm{C \# C}$ & 14.95 & 8 & 3 \\
\hline 115 & C sp & $\mathrm{CHN}$ & 39.64 & 28 & 20 \\
\hline 116 & C sp & $\mathrm{C \# N}(+)$ & 62.56 & 1 & 1 \\
\hline 117 & C sp & \#CSi & 0 & 2 & 1 \\
\hline
\end{tabular}


Table 7. Cont

\begin{tabular}{|c|c|c|c|c|c|}
\hline Entry & Atom Type & Neighbours & Contribution & Occurrences & Molecules \\
\hline 118 & C sp & \#NO & 58.07 & 2 & 1 \\
\hline 119 & $\mathrm{Csp}$ & $=\mathrm{N}=\mathrm{O}$ & 110.98 & 6 & 3 \\
\hline 120 & $\mathrm{~N} \mathrm{sp3}$ & $\mathrm{H} 2 \mathrm{C}$ & -18.62 & 5 & 5 \\
\hline 121 & N sp3 & $\mathrm{H} 2 \mathrm{C}(\mathrm{pi})$ & 15.49 & 129 & 98 \\
\hline 122 & N sp3 & $\mathrm{H} 2 \mathrm{~N}$ & 9.51 & 4 & 3 \\
\hline 123 & N sp3 & $\mathrm{H} 2 \mathrm{~S}$ & 45.92 & 9 & 9 \\
\hline 124 & N sp3 & $\mathrm{HC} 2$ & -104.07 & 6 & 3 \\
\hline 125 & N sp3 & HC2(pi) & -56.77 & 78 & 57 \\
\hline 126 & N sp3 & HC2(2pi) & -9.78 & 82 & 61 \\
\hline 127 & N sp3 & $\mathrm{HCN}(\mathrm{pi})$ & 21.22 & 7 & 5 \\
\hline 128 & N sp3 & $\mathrm{HCN}(2 \mathrm{pi})$ & 36.09 & 7 & 7 \\
\hline 129 & $\mathrm{~N}$ sp3 & $\mathrm{C} 3$ & -159.23 & 15 & 10 \\
\hline 130 & N sp3 & C3(pi) & -123.38 & 10 & 9 \\
\hline 131 & N sp3 & C3(2pi) & -83.83 & 27 & 21 \\
\hline 132 & $\mathrm{~N}$ sp3 & C3(3pi) & -43.15 & 12 & 6 \\
\hline 133 & $\mathrm{~N} \mathrm{sp3}$ & $\mathrm{C} 2 \mathrm{~N}(\mathrm{pi})$ & -75.07 & 3 & 3 \\
\hline 134 & $\mathrm{~N} \mathrm{sp3}$ & $\mathrm{C} 2 \mathrm{~N}(+)(\mathrm{pi})$ & -52.69 & 7 & 2 \\
\hline 135 & $\mathrm{~N} \mathrm{sp3}$ & $\mathrm{C} 2 \mathrm{~N}(2 \mathrm{pi})$ & 25.39 & 3 & 3 \\
\hline 136 & N sp3 & $\mathrm{C} 2 \mathrm{~N}(+)(2 \mathrm{pi})$ & -41.18 & 2 & 2 \\
\hline 137 & $\mathrm{~N} \mathrm{sp} 2$ & $\mathrm{C}=\mathrm{C}$ & -74.59 & 54 & 44 \\
\hline 138 & $\mathrm{~N} \mathrm{sp} 2$ & $\mathrm{C}=\mathrm{N}$ & 2.46 & 5 & 3 \\
\hline 139 & $\mathrm{~N} \mathrm{sp} 2$ & $=\mathrm{CN}$ & -98.01 & 7 & 7 \\
\hline 140 & N sp2 & $=\mathrm{CN}(+)$ & -14.76 & 1 & 1 \\
\hline 141 & $\mathrm{~N} \mathrm{sp} 2$ & $=\mathrm{CO}$ & -44.63 & 24 & 11 \\
\hline 142 & $\mathrm{~N} \mathrm{sp} 2$ & $\mathrm{~N}=\mathrm{N}$ & 17.43 & 3 & 2 \\
\hline 143 & $\mathrm{~N}$ aromatic & $\mathrm{H} 2: \mathrm{C}(+)$ & 4.65 & 4 & 2 \\
\hline 144 & $\mathrm{~N}$ aromatic & $\mathrm{HC}: \mathrm{C}(+)$ & 40.44 & 1 & 1 \\
\hline 145 & $\mathrm{~N}$ aromatic & $\mathrm{C} 2: \mathrm{C}(+)$ & -3.11 & 7 & 4 \\
\hline 146 & $\mathrm{~N}$ aromatic & :C2 & -0.16 & 50 & 33 \\
\hline 147 & $\mathrm{~N}(+) \mathrm{sp} 3$ & $\mathrm{H} 3 \mathrm{C}$ & -6.7 & 35 & 34 \\
\hline 148 & $\mathrm{~N}(+) \mathrm{sp} 3$ & $\mathrm{H} 2 \mathrm{C} 2$ & -73.79 & 4 & 4 \\
\hline 149 & $\mathrm{~N}(+) \mathrm{sp} 3$ & $\mathrm{HC} 3$ & -156.71 & 1 & 1 \\
\hline 150 & $\mathrm{~N}(+) \mathrm{sp} 3$ & $\mathrm{C} 4$ & -233.93 & 2 & 2 \\
\hline 151 & $\mathrm{~N}(+) \mathrm{sp} 2$ & $\mathrm{CO}=\mathrm{O}(-)$ & 9.71 & 72 & 49 \\
\hline 152 & $\mathrm{~N}(+) \mathrm{sp} 2$ & $=\mathrm{CO} 2(-)$ & -7.42 & 2 & 2 \\
\hline 153 & $\mathrm{~N}(+) \mathrm{sp} 2$ & $\mathrm{NO}=\mathrm{O}(-)$ & -2.08 & 10 & 5 \\
\hline 154 & $\mathrm{~N}(+)$ aromatic & $\mathrm{C}: \mathrm{C} 2$ & 0 & 1 & 1 \\
\hline 155 & $\mathrm{~N}(+) \mathrm{sp}$ & C\#C(-) & 25.34 & 3 & 3 \\
\hline 156 & $\mathrm{~N}(+) \mathrm{sp}$ & $\# \mathrm{CO}(-)$ & 0 & 1 & 1 \\
\hline
\end{tabular}


Table 7. Cont

\begin{tabular}{|c|c|c|c|c|c|}
\hline Entry & Atom Type & Neighbours & Contribution & Occurrences & Molecules \\
\hline 157 & $\mathrm{O}($ prim $)$ & $\mathrm{HC}$ & -23.36 & 106 & 60 \\
\hline 158 & $\mathrm{O}(\mathrm{sec})$ & $\mathrm{HC}$ & -16.25 & 117 & 50 \\
\hline 159 & $\mathrm{O}$ (tert) & $\mathrm{HC}$ & -3.34 & 6 & 6 \\
\hline 160 & $\mathrm{O}$ & $\mathrm{HC}(\mathrm{pi})$ & 4.78 & 218 & 157 \\
\hline 161 & $\mathrm{O}$ & $\mathrm{HN}(\mathrm{pi})$ & 16.33 & 3 & 3 \\
\hline 162 & $\mathrm{O}$ & $\mathrm{HSi}$ & 16.93 & 8 & 2 \\
\hline 163 & $\mathrm{O}$ & $\mathrm{C} 2$ & -70.39 & 60 & 29 \\
\hline 164 & $\mathrm{O}$ & C2(pi) & -39.71 & 125 & 88 \\
\hline 165 & $\mathrm{O}$ & C2(2pi) & -23.91 & 47 & 41 \\
\hline 166 & $\mathrm{O}$ & $\mathrm{CN}(2 \mathrm{pi})$ & -28.51 & 5 & 5 \\
\hline 167 & $\mathrm{O}$ & $\mathrm{CSi}$ & -30.4 & 36 & 9 \\
\hline 168 & $\mathrm{O}$ & N2(2pi) & 1.1 & 7 & 4 \\
\hline 169 & $\mathrm{O}$ & N2(+)(2pi) & -2.2 & 2 & 2 \\
\hline 170 & $\mathrm{O}$ & $\mathrm{Si} 2$ & -7.14 & 39 & 8 \\
\hline 171 & P3 & C3 & -2.25 & 1 & 1 \\
\hline 172 & P4 & $\mathrm{C} 3=\mathrm{O}$ & 2.25 & 1 & 1 \\
\hline 173 & $\mathrm{P} 4$ & $\mathrm{C}=\mathrm{OCl} 2$ & 0 & 1 & 1 \\
\hline 174 & S2 & $\mathrm{HC}$ & 10.73 & 1 & 1 \\
\hline 175 & S2 & $\mathrm{HC}(\mathrm{pi})$ & 16.07 & 5 & 5 \\
\hline 176 & S2 & $\mathrm{C} 2$ & -15.43 & 12 & 8 \\
\hline 177 & S2 & C2(pi) & -30.85 & 14 & 6 \\
\hline 178 & $\mathrm{~S} 2$ & C2(2pi) & -10.04 & 24 & 17 \\
\hline 179 & S2 & CS & -20.66 & 4 & 2 \\
\hline 180 & S2 & CS(pi) & 6.91 & 6 & 3 \\
\hline 181 & S4 & $\mathrm{C} 2=\mathrm{O}$ & 5.33 & 2 & 2 \\
\hline 182 & $\mathrm{~S} 4$ & $\mathrm{C} 2=\mathrm{O} 2$ & 15.56 & 5 & 5 \\
\hline 183 & S4 & $\mathrm{CN}=\mathrm{O} 2$ & 2.75 & 9 & 9 \\
\hline 184 & S4 & $\mathrm{CO}=\mathrm{O} 2(-)$ & -118.41 & 1 & 1 \\
\hline 185 & $\mathrm{Si}$ & $\mathrm{C} 4$ & -197.51 & 3 & 3 \\
\hline 186 & $\mathrm{Si}$ & $\mathrm{C} 3 \mathrm{O}$ & -100.79 & 4 & 2 \\
\hline 187 & $\mathrm{Si}$ & $\mathrm{C} 3 \mathrm{Cl}$ & -107.38 & 1 & 1 \\
\hline 188 & $\mathrm{Si}$ & $\mathrm{C} 2 \mathrm{O} 2$ & -38.26 & 11 & 3 \\
\hline 189 & $\mathrm{Si}$ & $\mathrm{CO} 3$ & 10.05 & 20 & 3 \\
\hline 190 & $\mathrm{Si}$ & $\mathrm{CCl} 3$ & 57.89 & 2 & 2 \\
\hline 191 & $\mathrm{Si}$ & $\mathrm{O} 4$ & 0 & 9 & 9 \\
\hline 192 & $(\mathrm{COH}) \mathrm{n}$ & $\mathrm{n}>1$ & 3.46 & 145 & 59 \\
\hline 193 & $\mathrm{H}$ & H Acceptor & 1.19 & 61 & 43 \\
\hline 194 & Endocyclic bonds & No of single bds & -1.44 & 998 & 149 \\
\hline
\end{tabular}


Table 7. Cont.

\begin{tabular}{cccccc}
\hline Entry & Atom Type & Neighbours & Contribution & Occurrences & Molecules \\
\hline 195 & Angle60 & & 0.97 & 15 & 2 \\
\hline 196 & Angle90 & & 0.31 & 12 & 6 \\
\hline 197 & Angle102 & & 2.16 & 284 & 83 \\
\hline A & Based on & Valid groups & 126 & 802 \\
\hline B & Goodness of fit & $r^{2}$ & 0.9915 & 734 \\
\hline C & Deviation & Average & 9.36 & 734 \\
\hline D & Deviation & Standard & 12.21 & 734 \\
\hline E & K-fold cv & K & 10 & 663 \\
\hline F & Goodness of fit & $q^{2}$ & 0.9874 & 663 \\
\hline G & Deviation & Average $(\mathrm{cv})$ & 11.1 & 663 \\
\hline H & Deviation & Standard $(\mathrm{cv})$ & 14.23 & 663 \\
\hline
\end{tabular}

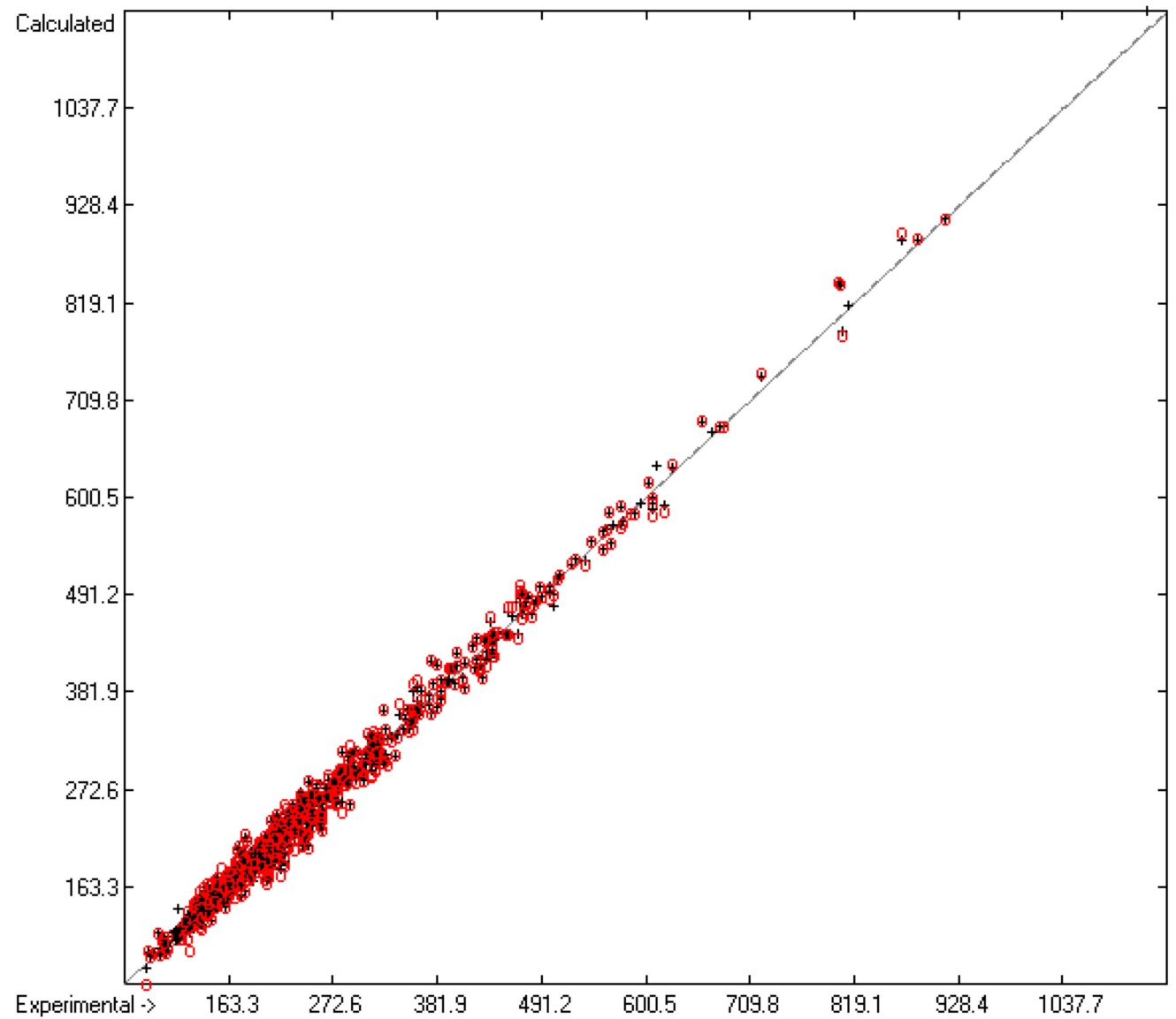

Figure 4. Correlation diagram of the $\mathrm{C}_{\mathrm{p}}(\mathrm{sol}, 298)$ data (in $\left.\mathrm{J} / \mathrm{mol} / \mathrm{K}\right)$. The cross-validation data are superimposed as red circles. $\left(n=734 ; r^{2}=0.9915 ; q^{2}=0.9874\right.$; regression line: intercept $=-0.0999$; slope $=0.9984)$. 


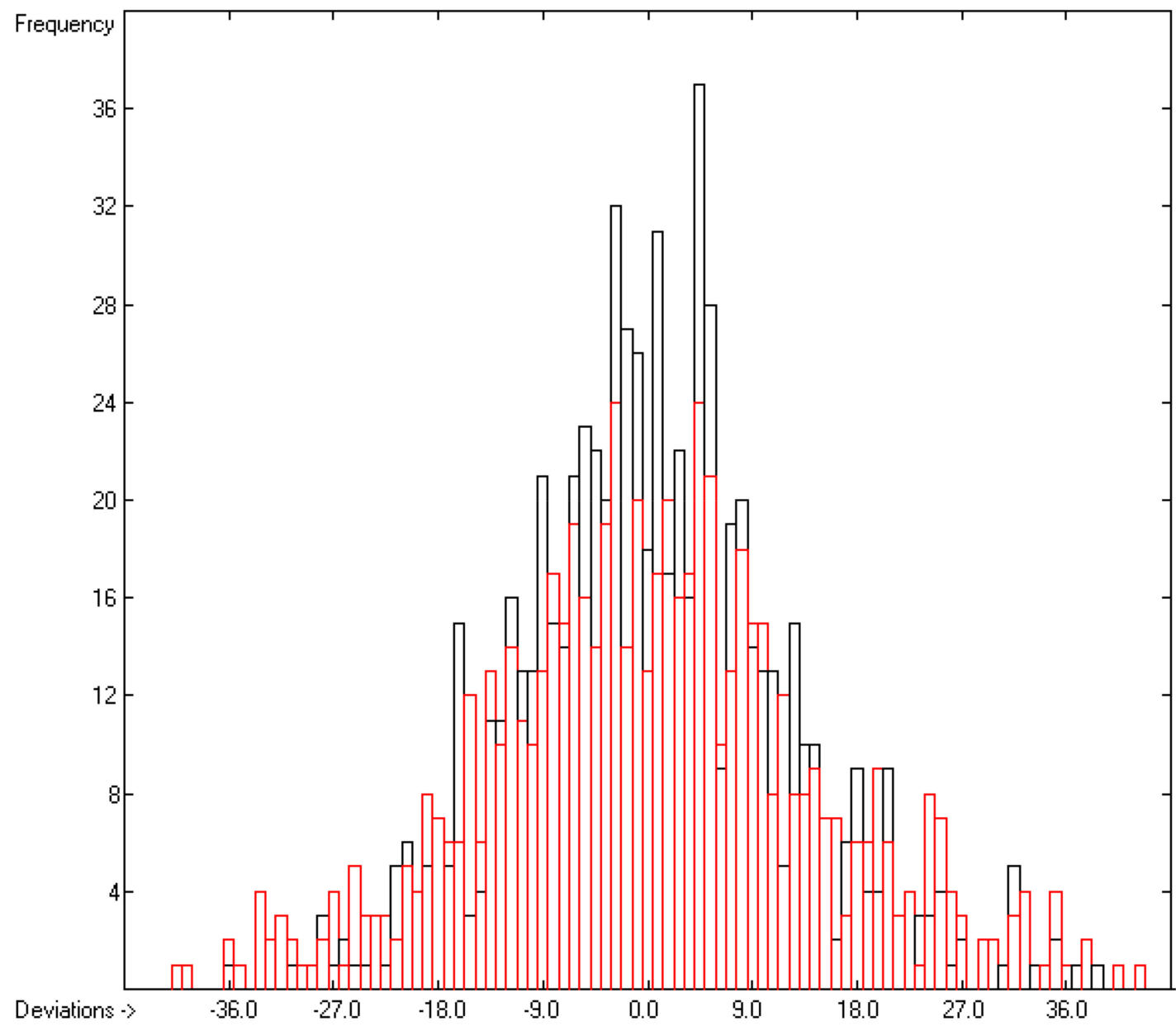

Figure 5. Histogram of the solid heat-capacity data. The deviations are in $\mathrm{J} / \mathrm{mol} / \mathrm{K}$. The cross-validation data are superimposed as red bars. ( $s= \pm 14.23$; Experimental value range: $78.7-1129 \mathrm{~J} / \mathrm{molK})$.

Hydrogen bridges are known to play a crucial role in the formation of the crystalline structure of solids (think of snowflakes or water ice). Since the $V_{m}$ approach of [1] is not able to include this effect directly, compounds containing $\mathrm{OH}$ groups were treated separately from the $\mathrm{OH}$-free molecules. In analogy to the observation made with the liquid alcohols one would then have expected that the $V_{m}$ approach again exhibited an unresolvable deficiency as concerning the deviations between experimental and predicted solid heat capacities of primary, secondary, and tertiary alcohols. Unfortunately, however, the enhanced extent of the scatter of the experimental $C_{p}($ sol) values in this compound's class concealed these suspected deviations. The present GA method on the other hand provided an indirect proof of the influence of the immediate neighbourhood of the $\mathrm{OH}$ group in the alcohol subclasses: a comparison of the contributions of the atom groups 157, 158, and 159 in Table $7(-23.36,-16.25$ and $-3.34 \mathrm{~J} / \mathrm{molK}$, respectively), assigned to the primary, secondary, and tertiary $\mathrm{OH}$ groups, immediately reveals that the primary alcohols exhibit the strongest hydrogen bridge effect, leading to the correspondingly largest decrease in the heat capacity due to the additional loss of freedoms of motion, followed by the secondary and the tertiary alcohols. The reason for this differentiation is the same as explained for that of the liquid alcohols in the prior section: the increase in the bulkiness around the $\mathrm{OH}$ group increasingly prevents hydrogen-bridge building. The separation of the alcohol subclasses in the present GA method also improved the reliability of the predicted $C_{p}($ sol,298) values. In Table 8 , the results of the GA and the $V_{m}$ method for 31 alkanols have been collected and compared with their experimental data. It is interesting to see that the largest deviations of the GA method coincide with large ones of the $\mathrm{V}_{\mathrm{m}}$ method (i.e. for 2,2-dimethyl-1,3-propanediol and 1,15-pentadecanediol), indicating that their 
experimental values are probably incorrect. General experience suggests that, in cases where the $V_{m}$ method exhibits a large deviation, it is the GA method that is more trustworthy.

Table 8. Experimental $C_{p}(s o l, 298)$ data of 31 alkanols, compared with prediction values calculated by the present GA and the $V_{m}[1] \operatorname{method}($ in $\mathrm{J} / \mathrm{mol} / \mathrm{K}$ ).

\begin{tabular}{|c|c|c|c|c|c|}
\hline Molecule Name & $\begin{array}{c}\mathrm{C}_{\mathrm{p}}(\mathrm{sol}, 298) \\
\text { GA-calc }\end{array}$ & Dev. $(\%)$ & $\begin{array}{c}\mathrm{C}_{\mathrm{p}}(\mathrm{sol}, 298) \\
\text { exp. }\end{array}$ & Dev. $(\%)$ & $\begin{array}{c}\mathrm{C}_{\mathrm{p}} \text { (sol,298) } \\
\mathrm{V}_{\mathrm{m}} \text {-calc. }[1]\end{array}$ \\
\hline 2-Methyl-2-propanol & 135.90 & 6.99 & 146.11 & 18.28 & 119.40 \\
\hline 2,2-Dimethyl-1,3-propanediol & 158.00 & 13.75 & 183.18 & 13.42 & 158.60 \\
\hline Erythritol & 164.20 & -1.42 & 161.90 & 0.99 & 160.30 \\
\hline cis-1,2-Cyclohexanediol & 168.00 & -4.74 & 160.40 & -4.68 & 167.90 \\
\hline trans-1,2-Cyclohexanediol & 168.00 & -2.94 & 163.20 & -3.00 & 168.10 \\
\hline Pentaerythritol & 174.40 & 7.43 & 188.40 & 3.24 & 182.30 \\
\hline Hexamethyleneglycol & 187.90 & 1.11 & 190.00 & 2.47 & 185.30 \\
\hline Xylitol & 206.90 & 0.05 & 207.00 & 10.14 & 186.00 \\
\hline Ethriol & 191.10 & 10.62 & 213.80 & 7.86 & 197.00 \\
\hline Inositol & 223.60 & -2.57 & 218.00 & 0.50 & 216.90 \\
\hline 2-Adamantanol & 193.30 & 6.71 & 207.20 & -6.13 & 219.90 \\
\hline 1-Adamantanol & 195.60 & 0.56 & 196.70 & -12.10 & 220.50 \\
\hline Dulcose & 246.00 & -3.14 & 238.50 & 3.31 & 230.60 \\
\hline Isoborneol & 243.10 & 6.88 & 261.06 & 10.21 & 234.40 \\
\hline Borneol & 243.10 & 6.88 & 261.06 & 9.68 & 235.80 \\
\hline 1,8-Octanediol & 238.90 & -1.07 & 236.36 & -0.23 & 236.90 \\
\hline Sorbitol & 242.30 & -1.38 & 239.00 & 0.50 & 237.80 \\
\hline Menthol & 250.70 & -0.24 & 250.10 & -0.72 & 251.90 \\
\hline 1,9-Nonanediol & 264.30 & -2.94 & 256.74 & -2.36 & 262.80 \\
\hline 1,10-Decanediol & 289.80 & -3.77 & 279.26 & -3.34 & 288.60 \\
\hline 1,11-Undecanediol & 315.20 & -5.85 & 297.79 & -5.58 & 314.40 \\
\hline Tri-t-butylmethanol & 351.80 & -0.34 & 350.60 & 6.36 & 328.30 \\
\hline 1,12-Dodecanediol & 340.70 & -3.17 & 330.23 & -3.05 & 340.30 \\
\hline 1-Tridecanol & 358.60 & 5.13 & 378.00 & 8.41 & 346.20 \\
\hline 1,13-Tridecanediol & 366.20 & 0.19 & 366.88 & 0.21 & 366.10 \\
\hline Myristyl alcohol & 384.00 & 1.03 & 388.00 & 4.28 & 371.40 \\
\hline 1,14-Tetradecanediol & 391.60 & -3.16 & 379.61 & -3.24 & 391.90 \\
\hline 1-Pentadecanol & 409.50 & -2.38 & 400.00 & 0.88 & 396.50 \\
\hline 1,15-Pentadecanediol & 417.10 & -10.50 & 377.45 & -10.66 & 417.70 \\
\hline 1-Hexadecanol & 435.00 & -3.08 & 422.00 & 0.09 & 421.60 \\
\hline 1,16-Hexadecanediol & 442.50 & -3.83 & 426.18 & -4.06 & 443.50 \\
\hline MAPD & & 4.00 & & 5.16 & \\
\hline
\end{tabular}

While the intermolecular interactions of $\mathrm{OH}$ groups exhibit a large influence on the heat capacity of solids, a similar effect of saturated cyclic structures over non-cyclic ones should not be expected as their interactions merely result from the weak dispersive forces. Beyond this-and in contrast to the conditions in the liquid phase-in a solid crystal not only the translational but also the intramolecular 
freedoms of motion are largely restricted independent of cyclic or non-cylic molecular moieties. This seems to be confirmed by the smaller contribution of the saturated endocyclic bonds (special group 194 in Table 7) of $-1.44 \mathrm{~J} / \mathrm{mol} / \mathrm{K}$ compared to that for the calculation of the liquid $\mathrm{C}_{\mathrm{p}}$ of $-3.92 \mathrm{~J} / \mathrm{mol} / \mathrm{K}$. However, as has been demonstrated by the comparison of some structurally closely related examples in [1], e.g., $\mathrm{o}-, \mathrm{m}-$, and $\mathrm{p}$-quinquephenyl, anthracene, phenanthrene, and various dimethylnaphthalenes, although aromatics, the chemical structure of a molecule itself has a very dominant effect on the crystalline structure, which again affects the experimental value of the solid heat capacity. In Table 9, a selection of saturated alkanes and cycloalkanes has been listed and their experimental solid heat capacities compared with the prediction values calculated by means of the present GA and the $V_{m}$ method [1].

Table 9. Experimental $C_{p}($ sol,298) data of 18 alkanes and cycloalkanes, compared with prediction values calculated by the present GA and the $V_{\mathrm{m}}$ [1] method (in J/mol/K).

\begin{tabular}{|c|c|c|c|c|c|}
\hline Molecule Name & $\begin{array}{c}\mathrm{C}_{\mathrm{p}}(\mathrm{sol}, 298) \\
\text { GA-Calc. }\end{array}$ & Dev. (\%) & $\begin{array}{c}\mathrm{C}_{\mathrm{p}}(\mathrm{sol}, 298) \\
\text { exp. }\end{array}$ & Dev. $(\%)$ & $\begin{array}{c}C_{p}(\text { sol, } 298) \\
V_{m} \text {-Calc. }[1]\end{array}$ \\
\hline Nortricyclene & 130.70 & -1.32 & 129.00 & -9.15 & 140.80 \\
\hline Norbornane & 163.80 & -8.48 & 151.00 & 0.93 & 149.60 \\
\hline Bicyclo[2.2.2]octane & 163.80 & -3.87 & 157.69 & -8.44 & 171.00 \\
\hline Adamantane & 183.30 & 3.53 & 190.00 & -5.95 & 201.30 \\
\hline Bicyclo[3.3.3] undecane & 236.10 & -10.74 & 213.20 & -9.19 & 232.80 \\
\hline Diamantane & 222.10 & 0.58 & 223.40 & -17.32 & 262.10 \\
\hline Perhydrophenanthrene & 279.60 & 3.42 & 289.50 & -0.73 & 291.60 \\
\hline Tri-t-butylmethane & 339.50 & 4.31 & 354.80 & 15.30 & 300.50 \\
\hline Cetane & 431.00 & 2.44 & 441.80 & 13.26 & 383.20 \\
\hline Octadecane & 481.90 & 0.77 & 485.64 & 11.70 & 428.80 \\
\hline Docosane & 583.80 & -3.58 & 563.60 & 7.59 & 520.80 \\
\hline 2,11-Dicyclohexyldodecane & 563.40 & -1.09 & 557.30 & 4.65 & 531.40 \\
\hline 1,1-Dicyclohexyldodecane & 565.20 & -0.46 & 562.60 & 5.44 & 532.00 \\
\hline Hexacosane & 685.60 & -3.69 & 661.20 & 7.43 & 612.10 \\
\hline Triacontane & 787.40 & 2.65 & 808.80 & 13.03 & 703.40 \\
\hline Dotriacontane & 838.40 & -4.02 & 806.00 & 7.07 & 749.00 \\
\hline Tetratriacontane & 889.30 & -0.21 & 887.40 & 10.45 & 794.70 \\
\hline Pentatriacontane & 914.70 & 0.13 & 915.90 & 10.74 & 817.50 \\
\hline MAPD & & 3.07 & & 8.80 & \\
\hline
\end{tabular}

A quick scan of the deviations of the $V_{m}$-calculated $C_{p}($ sol,298) values (column 5 in Table 9) immediately shows that the $V_{m}$ method systematically overestimates the solid heat capacity of the cycloalkanes (norbornane and the dicyclohexyldodecanes being exceptions), whereas that of the ring-free alkanes is systematically underestimated. Although the overestimation in the case of the cycloalkanes resembles the one found in the estimation of their liquid heat capacity, as demonstrated in Table 5, it does not seem far-fetched to assume that at least part of its extent lies in potentially more clearly defined crystalline structures as compared to the probably waxy consistence of the linear counterparts. The predicted $C_{p}(s o l, 298)$ values resulting from the present GA method, on the other hand, yield excellent conformation with the experimental data. The largest deviations are interestingly found for norbornane, one of the exceptions in the $\mathrm{V}_{\mathrm{m}}$ calculations, and bicyclo[3.3.3]undecane. For norbornane, the experimental value published by Steele [55] should be higher by ca. $8 \%$ to fit the respective deviations into the general picture of both prediction methods. For bicyclo[3.3.3] undecane, both prediction methods suggest a ca. $10 \%$ higher $\mathrm{C}_{\mathrm{p}}(\mathrm{sol}, 298)$ value than reported by Parker et al. [56]. 
In conformance with the findings of the $\log \mathrm{P}$ analysis in an earlier paper [6], the amino acids are assumed to exist in a zwitterionic form as solids (phenylglycine being an exception, as shown in Table 9 of [6], due to the lower basicity of the nitrogen atom conjugated to the phenyl ring). Accordingly, in Table 4, their carboxylate group is represented by entry 74, their alkyl- and dialkyl-ammonium functions by entries 148 and 149, respectively, and their immediate neighbours, the methyl and methylene groups, by the respective entries 4 and 11. Test calculations based on their non-ionic forms resulted in systematically and significantly overestimating the $C_{p}(\mathrm{sol}, 298)$ values, indicating that their corresponding atom groups in Table 4, (i.e., entry 73, representing the carboxylic acid, and entries 122 and 125, representing the alkyl- and dialkyl-amino groups, respectively) are not applicable in the heat-capacity evaluation of amino acids. These results, however, should not be interpreted as a confirmation of the zwitterionic form of the amino acids as solids, because the basis for the parameters representing the neutral alkyl- and dialkyl-amino groups is at present too small, and a recalibration of the group parameters of Table 4 by applying the non-ionic instead of the zwitter-ionic forms could well lead to better-conforming GA-based results of the non-ionic forms with the experimental data.

In contrast, analogous comparative calculations based on the $V_{\mathrm{m}}$ method [1] revealed only minor prediction differences between the ionic and the non-ionic forms, which was to be expected as the "true" molecular volumes of both the prototropic forms are very similar. Typical examples listed in Table 10 demonstrate these observations. The MAPD between the experimental data and those calculated for the zwitterionic forms in Table 10 was $3.36 \mathrm{~J} / \mathrm{mol} / \mathrm{K}$ on applying the GA method and $4.02 \mathrm{~J} / \mathrm{mol} / \mathrm{K}$ when using the $\mathrm{V}_{\mathrm{m}}$ approach.

Table 10. Comparison of the $\mathrm{Cp}(\mathrm{sol}, 298)$ data of the ionic and the non-ionic forms of amino acids calculated by the present GA and the $\mathrm{V}_{\mathrm{m}}[1]$ method (in $\mathrm{J} / \mathrm{mol} / \mathrm{K}$ ).

\begin{tabular}{|c|c|c|c|c|c|}
\hline \multirow[t]{2}{*}{ Molecule name } & \multicolumn{2}{|c|}{$C_{p}($ sol,298) GA-calc. } & \multirow[t]{2}{*}{$C_{p}($ sol,298) Exp. } & \multicolumn{2}{|c|}{$C_{p}\left(\right.$ sol,298) $V_{m}$-Calc. [1] } \\
\hline & Non-Ionic & Zwitter-Ionic & & Zwitter-Ionic & Non-Ionic \\
\hline Glycine & 120.20 & 89.90 & 99.30 & 95.90 & 91.30 \\
\hline Alanine & 147.60 & 116.50 & 119.90 & 118.50 & 116.10 \\
\hline N-Methylglycine & 136.00 & 122.40 & 118.20 & 119.10 & 116.90 \\
\hline Serine & 152.70 & 121.70 & 135.60 & 126.20 & 126.50 \\
\hline Aminobutyric acid & 173.00 & 142.00 & 146.40 & 140.90 & 140.70 \\
\hline Proline & 162.20 & 137.30 & 150.40 & 149.80 & 150.90 \\
\hline Threonine & 183.00 & 152.00 & 155.31 & 153.30 & 154.70 \\
\hline Aspartic acid & 193.00 & 162.00 & 155.18 & 155.10 & 156.00 \\
\hline Asparagine & 189.80 & 158.70 & 159.80 & 157.60 & 159.30 \\
\hline Valine & 196.70 & 165.60 & 165.00 & 162.90 & 165.40 \\
\hline 5-Aminopentanoic acid & 196.60 & 166.30 & 163.70 & 164.30 & 166.60 \\
\hline Ornithine & 225.40 & 194.40 & 191.20 & 179.20 & 183.60 \\
\hline Glutamine & 214.00 & 183.00 & 184.18 & 182.30 & 186.50 \\
\hline Leucine & 222.10 & 191.10 & 200.80 & 183.90 & 188.20 \\
\hline Isoleucine & 222.10 & 191.10 & 188.28 & 184.70 & 189.90 \\
\hline Methionine & 238.50 & 207.40 & 205.16 & 189.10 & 194.30 \\
\hline N-Phenylglycine & 196.10 & 162.20 & 177.40 & 194.60 & 198.60 \\
\hline Phenylalanine & 232.20 & 201.10 & 203.10 & 215.50 & 221.60 \\
\hline 8-Aminooctanoic acid & 273.00 & 242.70 & 251.70 & 232.80 & 241.90 \\
\hline Tyrosine & 248.20 & 217.10 & 216.44 & 236.20 & 238.10 \\
\hline Tryptophane & 268.30 & 237.20 & 238.15 & 252.00 & 263.90 \\
\hline
\end{tabular}


As a consequence, and despite their excellent predictive quality, both the GA- and the $\mathrm{V}_{\mathrm{m}}$-based methods are not suitable to answer the question as to which form the amino acids exist as solids.

In the optimization process for the evaluation of the atom and special group contributions of Table 7, it turned out that 51 compounds had to be eliminated as outliers and have been collected in a separate list, available in the Supplementary Materials. This list again largely corresponded to the one resulting from the $\mathrm{V}_{\mathrm{m}}$ optimization procedure. The remaining 800 compounds finally supported 126 atom and special groups valid for $\mathrm{C}_{\mathrm{p}}(\mathrm{sol}, 298)$ predictions (row A in Table 7). Despite the smaller number of valid groups as compared to that of Table 3 for the liquid heat capacities, with $65 \%$ they cover an even slightly larger percentage of ChemBrain's representative database.

\section{Conclusions}

The present paper is extending the series of publications [6-9] about the direct and indirect calculation of 14 molecular properties (enthalpy of combustion, formation, vaporization, sublimation and solvation, entropy of fusion, $\log \mathrm{P}_{\mathrm{o} / \mathrm{w}}, \log \mathrm{S}, \log \gamma_{\mathrm{inf}}$, refractivity, polarizability, toxicity, liquid viscosity, and surface tension) by means of a single computer algorithm, adding two further molecular properties, the heat capacity for the liquid and solid phase of molecules. A comparison of the prediction quality of the present GA method for the heat capacities with that based on the "true" molecular volume [1] published recently proved a significantly higher accuracy over the latter. This was accomplished by directly addressing the deficiencies of the molecular volume approach, particularly its inevitable neglect of the intermolecular formation of hydrogen bridges of the $\mathrm{OH}$ groups as well as its non-consideration of the cyclization effect of saturated rings over ring-open forms on the heat capacity of both the liquid and solid phases. However, since the group additivity method in principle lacks the comprehensive range of the molecular volume approach, both prediction methods are beneficial in their own right-and they complement each other all the more, as in most cases they confirm each other's result within explicable deviations. Therefore, in the present ongoing project ChemBrain IXL, version 5.9, available from Neuronix Software (www.neuronix.ch, Rudolf Naef, Lupsingen, Switzerland), the results of both methods are added to the database, the group-additivity result carrying the suffix "calc" and the volume-derived one the suffix "pred".

Supplementary Materials: Supplementary materials can be accessed at http://www.mdpi.com/1420-3049/25/5/ $1147 / \mathrm{s} 1$. The lists of 3D structures of the compounds and their experimental values used for the liquid and solid heat-capacities calculations are available online as standard SDF files under the names names "S01. Compounds List for Cp (liq,298) calculations.sdf" and "S02. Compounds List for Cp $($ sol,298) calculations.sdf", respectively. The lists of compounds and their experimental and calculated $C_{p}$ values are available as doc files under the names " S03. Experimental vs. calculated Cp(liq,298) Data Table.doc" and " S04. Experimental vs. calculated Cp(sol,298) Data Table.doc". The lists of outliers are available as excel files under the names "S05. Outliers of Cp(liq,298) by GA approach.xls" and "S06. Outliers of Cp $(\mathrm{sol}, 298)$ by GA approach.xls". The figures are available as tif files and the tables as doc files under the names given in the text.

Funding: This research received no funding.

Acknowledgments: R. Naef is indebted to W.E. Acree of the University of North Texas for his support in the collection of literature references and for valuable discussions. He is also indebted to the library of the University of Basel for enabling full and free access to its electronic literature database.

Conflicts of Interest: The author declares no conflict of interest.

\section{Abbreviations}

- $\quad$ GA: atom-group additivity

- $\quad \mathrm{V}_{\mathrm{m}}$ : "true" molecular volume

\section{References}

1. Naef, R. Calculation of the isobaric heat capacities of the liquid and solid phase of organic compounds at and around 298.15 K based on their "True" molecular volume. Molecules 2019, 24, 1626. [CrossRef] [PubMed] 
2. Gardas, R.L.; Coutinho, J.A.P. A group contribution method for heat capacity estimation of ionic liquids. Ind. Eng. Chem. Res. 2008, 47, 5751-5757. [CrossRef]

3. Benson, S.W.; Buss, J.H. Additivity rules for the estimation of molecular properties. Thermodynamic properties. J. Chem. Phys. 1958, 29, 546-572. [CrossRef]

4. Zàbransky, M.; Ruzicka, V. Estimation of the heat capacities of organic liquids as a function of temperature using group additivity: An amendment. J. Phys. Chem. Ref. Data 2004, 33, 1071-1081.

5. Chickos, J.S.; Hesse, D.G.; Liebman, J.F. A group additivity approach for the estimation of heat capacities of organic liquids and solids at 298 K. Struct. Chem. 1993, 4, 261-269. [CrossRef]

6. Naef, R. A generally applicable computer algorithm based on the group additivity method for the calculation of seven molecular descriptors: Heat of combustion, $\log \mathrm{PO} / \mathrm{W}, \mathrm{LogS}$, refractivity, polarizability, toxicity and LogBB of organic compounds; scope and limits of applicability. Molecules 2015, 20, 18279-18351. [CrossRef]

7. Naef, R.; Acree, W.E. Calculation of five thermodynamic molecular descriptors by means of a general computer algorithm based on the group-additivity method: Standard enthalpies of vaporization, sublimation and solvation, and entropy of fusion of ordinary organic molecules and total phase-change entropy of liquid crystals. Molecules 2017, 22, 1059. [CrossRef]

8. Naef, R.; Acree, W.E. Application of a general computer algorithm based on the group-additivity method for the calculation of two molecular descriptors at both ends of dilution: Liquid viscosity and activity coefficient in water at infinite dilution. Molecules 2018, 23, 5. [CrossRef]

9. Naef, R.; Acree, W.E., Jr. Calculation of the surface tension of ordinary organic and ionic liquids by means of a generally applicable computer algorithm based on the group-additivity method. Molecules 2018, 23, 1224. [CrossRef]

10. Hardtwig, E. Fehler-und Ausgleichsrechnung. Hochschultaschenbücher 262/262a; Bibliographisches Institut AG: Mannheim, Germany, 1968.

11. Wong, W.-K.; Westrum, E.F., Jr. Thermodynamics of globular molecules. XVII. Heat capacities and transition behavior of bicyclo[2.2.2] octane and bicyclo[2.2.2]octene. J. Phys. Chem. 1970, 74, 1303-1308. [CrossRef]

12. Figueroa-Gerstenmaier, S.; Cabanas, A.; Costas, M. Self-association and complex formation in alcohol-unsaturated hydrocarbon systems. Heat capacities of linear alcohols mixed with alkenes and alkynes. Phys. Chem. Chem. Phys. 1999, 1, 665-674. [CrossRef]

13. Zaitsau, D.H.; Emel'yanenko, V.N.; Pimerzin, A.A.; Verevkin, S.P. Benchmark properties of biphenyl as a liquid organic hydrogen carrier: Evaluation of thermochemical data with complementary experimental and computational methods. J. Chem. Thermodyn. 2018, 122, 1-12. [CrossRef]

14. Mahnel, T.; Pokorny, V.; Fulem, M.; Sedmidubskym, D.; Ruzicka, K. Measurement of low-temperature heat capacity by relaxation technique: Calorimeter performance testing and heat capacity of benzo[b]fluoranthene, benzo[k]fluoranthene, and indeno[1,2,3-cd]pyrene. J. Chem. Thermodyn. 2020, 142, 105964. [CrossRef]

15. Chang, S.-S.; Westrum, E.F., Jr. Heat Capacities and Thermodynamic Properties of Globular Molecules. I. Adamantane and Hexamethylenetetramine. J. Phys. Chem. 1960, 64, 1547-1551. [CrossRef]

16. Mendoza-Ruiz, E.A.; Mentado-Morales, J.; Flores-Segura, H. Standard molar enthalpies of formation and phase changes of Tetra-N-phenylbenzidine and 4,4'-Bis (N-carbazolyl)-1,1'-biphenyl. J. Therm. Anal. Calor. 2019, 135, 2337-2345. [CrossRef]

17. Van Bommel, M.J.; Van Miltenburg, J.C.; Schuijff, A. Heat-capacity measurements and thermodynamic functions of 1,3,5-triazine and 1,3,5-trioxane. J. Chem. Thermodyn. 1988, 20, 397-403. [CrossRef]

18. Piekarski, H.; Tkaczyk, M.; Tyczynska, M. Heat capacity and phase behavior of aqueous diethylene glycol n-pentyl ether by DSC. Thermochim. Acta 2012, 550, 19-26. [CrossRef]

19. Wasiak, M.; Tkaczyk, M.; Piekarski, H. Heat capacity and phase behaviour of aqueous solutions of triethylene glycol monopentyl ether. Two point scaling analysis. Fluid Phase Equil. 2017, 431, 16-23. [CrossRef]

20. Emel'yanenko, V.N.; Zaitsau, D.H.; Pimerzin, A.A.; Verevkin, S.P. Benchmark properties of diphenyl oxide as a potential liquid organic hydrogen carrier: Evaluation of thermochemical data with complementary experimental and computational methods. J. Chem. Thermodyn. 2018, 125, 149-158. [CrossRef]

21. Ashrafi, F.; Saadati, R.; Behboodi, A. Modeling and theoretical calculation of liquid heat capacity of alcohols and aldehydes using QSPR. African J. Pure Appl. Chem. 2008, 2, 116-120.

22. Campos, J.B.; Martinez-Gomez, A.J.; Orozco-Guareno, E. Design and building of an isoperibolic calorimeter: Measurements of enthalpy of formation for derivatives of glycidol. Meas. Sci. Technol. 2019, 30, 035902. [CrossRef] 
23. Buchholz, H.; Hylton, R.K.; Brandenburg, J.G.; Seidel-Morgenstern, A.; Lorenz, H.; Stein, M.; Price, S.L. The thermochemistry of racemic and enantiopure molecular crystals for predicting enantiomer separation. Cryst. Growth Des. 2017, 17, 4676-4686. [CrossRef]

24. Nikitin, E.D.; Popov, A.P.; Bogatishcheva, N.S.; Faizullin, M.Z. Critical temperatures and pressures, heat capacities, and thermal diffusivities of levulinic acid and four n-alkyl levulinates. J. Chem. Thermodyn. 2019, 135, 233-240. [CrossRef]

25. Su, C.; Zhu, C.; Ye, F.Y.Z.; Liu, X.; He, M. Isobaric molar heat capacity of ethyl octanoate and ethyl decanoate at pressures up to $24 \mathrm{Mpa}$. Chem. Eng. Data 2018, 63, 2252-2256. [CrossRef]

26. Van Bommel, M.J.; Oonk, H.A.J.; Van Miltenburg, J.C. Heat Capacity measurements of 13 methyl esters of n-carboxylic acids from methyl octanoate to methyl eicosanoate between $5 \mathrm{~K}$ and $350 \mathrm{~K}$. J. Chem. Eng. Data 2004, 49, 1036-1042. [CrossRef]

27. Xu, J.; Li, S.; Zeng, Z.; Xue, W. Heat capacity, density, vapor pressure, and enthalpy of vaporization of isoamyl DL-lactate. J. Chem. Eng. Data 2019, 64, 3793-3798. [CrossRef]

28. Neau, S.H.; Flynn, G.L. Solid and liquid heat capacities of n-alkyl para-aminobenzoates near the melting point. Pharmaceut. Res. 1990, 7, 1157-1162. [CrossRef]

29. Chorazewski, M.; Goralski, P.; Tkaczyk, M. Heat capacities of 1-chloroalkanes and 1-bromoalkanes within the temperature range from $284.15 \mathrm{~K}$ to $353.15 \mathrm{~K}$. A group additivity and molecular connectivity analysis. J. Chem. Eng. Data 2005, 50, 619-624. [CrossRef]

30. Goralski, P.; Tkaczyk, M.; Chorazewski, M. Heat capacities of $\alpha, \omega$-dichloroalkanes at temperatures from 284.15 K to $353.15 \mathrm{~K}$ and a group additivity analysis. J. Chem. Eng. Data 2003, 48, 492-496. [CrossRef]

31. Lipovska, M.; Schmidt, H.-G.; Rohac, V.; Ruzicka, V.; Wolf, G.; Zabransky, M. Heat capacities of three isomeric chlorobenzenes and of three isomeric chlorophenols. J. Therm. Anal. Calor. 2002, 68, 753-766. [CrossRef]

32. Goralski, P.; Piekarski, H. Heat capacities and densities of some liquid chloro-, bromo-, and bromochloro-substituted benzenes. J. Chem. Eng. Data 2007, 52, 655-659. [CrossRef]

33. Michalski, D.; Perry, R.T.; White, M.A. Additivity of guest and host properties in clathrates: A thermodynamic and Raman spectroscopic investigation of HPTB-based solids. J. Phys.: Condens. M. 1996, 8, 1647-1661. [CrossRef]

34. Roux, M.V.; Temprado, M.; Jimenez, P.; Guzman-Mejia, R.; Juaristi, E.; Chickos, J.S. Heat capacities of thiane sulfones and thiane sulfoxide Refining of $C_{p}$ group values for organosulfur compounds and their oxides. Thermochim. Acta 2003, 406, 9-16. [CrossRef]

35. Zhang, Z.Y.; Yang, M.L. Heat capacity and phase transition of 2-amino-2-methyl-1,3-propanediol from 280K to the melting point. Thermochim. Acta 1990, 169, 263-269. [CrossRef]

36. Chiu, L.-F.; Liu, H.-F.; Li, M.-H. Heat capacity of alkanolamines by differential scanning calorimetry. J. Chem. Eng. Data 1999, 44, 631-636. [CrossRef]

37. Soares, B.P.; Stejfa, V.; Ferreira, O.; Pinho, S.P.; Ruzicka, K.; Fulem, M. Vapor pressures and thermophysical properties of selected ethanolamines. Fluid Phase Equil. 2018, 473, 245-254. [CrossRef]

38. Perisanu, S.; Contineanu, I.; Neacsu, A.; Notario, R.; Roux, M.V.; Liebman, J.F.; Dodson, B.J. Thermochemistry and quantum chemical calculations of two dibenzocycloalkane nitriles. Struct. Chem. 2011, 22, 89-94. [CrossRef]

39. Stejfa, V.; Fulem, M.; Ruzicka, K. Vapor pressure of 4-ethylmorpholine revisited: Thermodynamically consistent vapor pressure equation. J. Chem. Eng. Data 2019, 644, 1605-1610. [CrossRef]

40. Tyunina, V.V.; Krasnov, A.V.; Tyunina, E.Y.; Badelin, V.G.; Rybkin, V.V. Enthalpies of sublimation of L-methionine and DL-methionine: Knudsen's effusion mass spectrometric study. J. Chem. Thermodyn. 2019, 135, 287-295. [CrossRef]

41. Abdelaziz, A.; Zaitsau, D.H.; Buzyurov, A.; Minakov, A.A.; Verevkin, S.P.; Schick, C. Fast scanning calorimetry: Sublimation thermodynamics of low volatile and thermally unstable compounds. Thermochim. Acta 2019, 676, 249-262. [CrossRef]

42. Stejfa, V.; Fulem, M.; Ruzicka, K. Thermodynamic study of selected monoterpenes IV. J. Chem. Thermodyn. 2019. [CrossRef]

43. Zhang, G.-Y.; Jin, S.-H.; Li, L.-J.; Li, Z.-H.; Shu, Q.-H.; Wang, D.-Q.; Zhang, B.; Li, Y.-K. Evaluation of thermal hazards and thermokinetic parameters of 3-amino-4-amidoximinofurazan by ARC and TG. J. Therm. Anal. Calor. 2016, 126, 1223-1230. [CrossRef] 
44. Li, R.; Hua, Y.; Tan, Z.; Shi, Q. Low temperature calorimetry of 3-fluoro-5-(3-pyridinyloxy) benzenamine and N-[3-fluoro-5-(3-Pyridinyloxy)phenyl]-N'-3-pyridinyl urea. Intern. J. Thermodyn. 2017, 20, 153-157. [CrossRef]

45. Baird,Z.S.; Dahlberg, A.; Uusi-Kyyny, P.; Osmanbegovic, N.; Witos, J.; Helminen, J.; Cederkrantz, D.; Hyväri, P.; Alopaeus, V.; Kilpeläinen, I.; et al. Physical properties of 7-methyl-1,5,7-triazabicyclo[4.4.0]dec-5-ene (mTBD). Intern. J. Thermophys. 2019, 40, 71. [CrossRef]

46. Liu, Y.; Di, Y.; Di, Y.; Qiao, C.; Che, F.; Yuan, F.; Yue, K.; Zhou, C. The studies of structure, thermodynamic properties and theoretical analyses of 2-[(4-nitro-benzoyl)-hydrazone]-propionic acid. J. Mol. Struct. 2019, 1184, 532-537. [CrossRef]

47. Vilas-Boas, S.M.; Pokorny, V.; Stejfa, V.; Ferreira, O.; Pinho, S.P.; Ruzicka, K.; Fulem, M. Vapor pressure and thermophysical properties of eugenol and (+)-carvone. Fluid Phase Equil. 2019, 499, 112248. [CrossRef]

48. Skotnicki, M.; Drogon, A.; Calvin, J.J.; Rosen, P.F.; Woodfield, B.F.; Pyda, M. Heat capacity and enthalpy of indapamide. Thermochim. Acta 2019, 674, 36-43. [CrossRef]

49. Cai, M.; Zhou, T.-H.; Li, Y.-N.; Xu, K.-Z. Two interesting derivatives of 1-amino-1-hydrazino-2,2-dinitroethylene (AHDNE): Synthesis and thermal properties. J. Therm. Anal. Calor. 2019. [CrossRef]

50. Doncaster, A.M.; Walsh, R. Thermochemistry of silicon-containing compounds. J. Chem. Soc. Faraday Trans. 1986, 82, 707-717. [CrossRef]

51. Waliszewski, D.; Stepniak, I.; Piekarski, H.; Lewandowski, A. Heat capacities of ionic liquids and their heats of solution in molecular liquids. Thermochim. Acta 2005, 433, 149-152. [CrossRef]

52. Lopez-Bueno, C.; Bugallo, D.; Leboran, V.; Rivadulla, F. Sub- $\mu$ L measurements of the thermal conductivity and heat capacity of liquids. Phys.Chem.Chem.Phys. 2018, 20, 7277. [CrossRef] [PubMed]

53. Zaitsau, D.H.; Schmitz, A.; Janiak, C.; Verevkin, S.P. Heat capacities of ionic liquids based on tetrahydrothiophenium cation and NTf2 anion. Thermochim. Acta 2020, 686, 178547. [CrossRef]

54. Huelsekopf, M.; Ludwig, R. Temperature dependence of hydrogen bonding. J. Mol. Liq. 2000, 85, $105-125$. [CrossRef]

55. Steele, W.V. The standard enthalpies of formation of a series of C7 bridged-ring hydrocarbons: Norbornane, norbornene, nortricyclene, norbornadiene, and quadricyclane. J. Chem. Thermodyn. 1978, 10, 919-927. [CrossRef]

56. Parker, W.; Steele, W.V.; Watt, I. A high-precision aneroid static-bomb combustion calorimeter for samples of about $20 \mathrm{mg}$. The standard enthalpy of formation of bicyclo[3.3.3]undecane. J. Chem. Thermodyn. 1975, 7, 795-802. [CrossRef]

Sample Availability: Samples of the compounds are not available.

(C) 2020 by the author. Licensee MDPI, Basel, Switzerland. This article is an open access article distributed under the terms and conditions of the Creative Commons Attribution (CC BY) license (http://creativecommons.org/licenses/by/4.0/). 